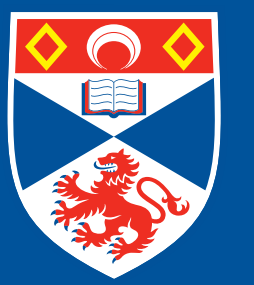

University of

St Andrews

Factor Complementarity and Labour Market Dynamics

$+$

$r$

(D)

$\stackrel{+}{0}$

$\mapsto$

$\bullet$

$\varangle$

占

ט

官

?

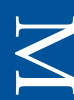

ט

ค

H

0

(D)

0

O

F

0

官

$\mapsto$.

ค

$\triangleright$

$F$

D

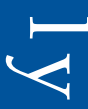

n

$\omega$.

(s)

CDMA Working Paper Series No. 1411

19 Nov 2014

JEL Classification: E24, E25, E32, J64

Keywords: CES, Deep Habits, Search and Matching, Bayesian estimation 


\title{
Factor Complementarity and Labour Market Dynamics*
}

\author{
Federico Di Pace ${ }^{\dagger}$ \\ University of St Andrews
}

\author{
Stefania Villa \\ KU Leuven \& University of Foggia
}

November 19, 2014

\begin{abstract}
We propose and estimate a dynamic stochastic general equilibrium model featuring search and matching frictions, deep habits and a CES production function. The model successfully replicates the cyclical properties of labour market variables in the US economy for three main reasons. First, the endogenous mechanisms of the model - factor complementarity, deep habits and unemployment benefits - play a key role for explaining the amplification in unemployment and vacancies. Second, factor-biased productivity innovations are important exogenous sources of labour market dynamics. Third, demand-side innovations induce markup fluctuations consistent with the deep habits mechanism.
\end{abstract}

Keywords: CES, Deep Habits, Search and Matching, Bayesian estimation

JEL codes: E24, E25, E32, J64

${ }^{*}$ Without implication, we would like to thank Yunus Aksoy, Fabio Canova, Cristiano Cantore, David de la Croix, Michael Dotsey, Matthias Hertweck, Miguel Leon-Ledesma, Vivien Lewis, Giovanni Melina, Antonella Trigari, Stephen Wright and conference and seminar participants at the 45th annual Money Macro and Finance conference, the 28th annual congress of the European Economic Association, the 19th International CEF Conference, the XXXVIII Simposio of the Spanish Economic Association and Birkbeck College for very useful comments and suggestions. A previous version of this paper circulated as "Re-distributive Shocks and Labour Market Dynamics".

${ }^{\dagger}$ School of Economics and Finance, Castlecliffe, The Scores, University of St Andrews, Fife KY16 9AR. E-mail: fndp@st-andrews.ac.uk.

${ }^{\ddagger}$ Center for Economic Studies, KU Leuven, 3000 Leuven, Belgium and Department of Economics, University of Foggia, 71100 Foggia, Italy. E-mail: stefania.villa@unifg.it. 


\section{Introduction}

Shimer (2005) shows that the standard search and matching model driven purely by Total Factor Productivity (TFP) innovations is unable to match the volatility of labour market variables observed in the US data. This lack of amplification in unemployment and vacancies is known in the literature as the unemployment volatility puzzle. A wide range of solutions have been proposed in an attempt to improve the performance of the standard search and matching model. These solutions can be classified into endogenous and exogenous mechanisms. The purpose of our study is to empirically validate, through the lenses of an estimated general equilibrium model, the role of three endogenous amplification mechanisms - factor complementarity, deep habits and unemployment benefits - and to quantify the extent to which exogenous innovations matter for amplification in labour market variables.

To this end, we develop and estimate, with US data using Bayesian techniques, a Dynamic Stochastic General Equilibrium (DSGE) model featuring search and matching frictions and nominal price rigidities. We adopt a balanced approach that changes the structure of the standard search and matching model along the supply and demand sides. Our model features a Constant Elasticity of Substitution (CES) production function with factor-biased innovations (e.g. León-Ledesma et al., 2010a). The demand-side of our model features deep habits in (private and public) consumption as in Ravn et al. (2006). The deep habits mechanism changes the pricing behaviour of firms, generating endogenous fluctuations in mark-ups that are not due to price rigidities. As standard in the literature, we consider unemployment benefits as an additional source of endogenous amplification.

The closest study to ours is Cantore et al. (2014). Their study analyses the effects of fiscal policy on employment and output during the recovery phase of the business cycle in a model calibrated to the US featuring a CES production function and deep habits. Our model, instead, displays a wide range of structural innovations, an active role for monetary policy and instantaneous matching. The aim of our paper is to empirically address the following research question: What is the role of the different endogenous mechanisms of amplification for explaining labour market dynamics and how do they interact with factor-biased productivity and demandside innovations?

One strand of the literature has attempted to find solutions to the unemployment volatility puzzle by introducing structural modifications to the standard model while preserving TFP innovations as the main sources of exogenous fluctuations. Hagedorn and Manovskii (2008) (HM henceforth) argue for an alternative calibration of the standard search and matching model. Costain and Reiter (2008) point out that this calibration implies an implausibly large elasticity of unemployment to unemployment benefits. Di Pace and Faccini (2012) propose a mechanism that changes the pricing decision of firms through deep habits in private consumption. The study of more general production functions such as CES production functions (that analyses the interplay between capital-labour complementarity and factor-biased technology innovations) has not yet been applied to address the unemployment volatility puzzle but it has been adopted in many applications (see Choi and Ríos-Rull, 2009; León-Ledesma et al., 2010a,b; Cantore et al., 2012; Klump et al., 2012; McAdam and Willman, 2013). Our work is the first to study the role of factor complementarity as an alternative mechanism of amplification. ${ }^{1}$

Another strand of the literature has sought to improve the performance of the standard search and matching model by introducing alternative exogenous innovations. Rotemberg (2008) and

\footnotetext{
${ }^{1}$ A popular solution to the puzzle introduces wage rigidities into the standard model. See Hall (2005), Shimer (2005), Gertler et al. (2008), Gertler and Trigari (2009) and Blanchard and Gali (2010) for a discussion on wage rigidities. Microeconometric evidence by Pissarides (2009) and Haefke et al. (2013) is suggestive that wages for newly hired workers are more cyclical than average wages. In a recent paper, however, Gertler et al. (2014) provide evidence in favour of wage rigidities for the newly hired. Other solutions have been proposed by Reiter (2007), Christoffel and Kuester (2008), Guerrieri (2008), Quadrini and Trigari (2008), Gomes (2011), Menzio and Shi (2011), Robin (2011), Alves (2012), Petrosky-Nadeau (2013), amongst others.
} 
Krause et al. (2008) show that price-elasticity innovations can help generate amplification in labour market variables. ${ }^{2}$ Gertler et al. (2008) and Faccini and Ortigueira (2010) argue that investment-specific innovations are important sources of labour market variation. Furlanetto and Groshenny (2013) find that matching efficiency innovations are relevant during "abnormal times". Monacelli et al. (2011) and Zanetti (2013) investigate the role of credit market innovations to match labour market dynamics in economies featuring financial frictions. The dynamics of our model is driven by three supply-side innovations (factor-biased productivity and matching efficiency innovations) and four demand-side innovations (preference, investment-specific, monetary and fiscal innovations). To the best of our knowledge, this study is the first one to estimate the role of factor-biased productivity innovations in a model featuring search and matching frictions. ${ }^{3}$

We find that the model is able to replicate reasonably well the volatility in unemployment and vacancies present in the US data. This property of the data can be explained through the interaction of endogenous and exogenous sources of amplification. Concerning the latter, we find an important role for both supply-side and demand-side innovations. Labour-augmenting innovations explain fluctuations over shorter horizons and capital-augmenting productivity innovations over the medium and long term. This result follows from the fact that the estimated model gives strong support for factor complementarity in the production process. We find that demand-side innovations explain more than one-third of the unconditional variance of unemployment and vacancies because they generate counter-cyclical mark-up fluctuations that are line in with the deep habits mechanism. A fall in mark-ups after an expansionary demand-side innovation increases the marginal revenue product of employment resulting in more vacancy creation.

Regarding the endogenous sources of amplification, the combination of deep habits, unemployment benefits and factor complementarity helps explain large part of the amplification in labour market variables. We find posterior mean estimates of the total replacement ratio and deep habits in private consumption that are high and statistically significant. Moreover, the deep habits mechanism adds additional endogenous persistence in vacancies as in Fujita and Ramey (2007). The posterior mean estimate of the elasticity of substitution is significantly lower than one, which gives empirical support for strong factor complementary. Hence, expansionary productivity innovations affecting one factor of production increase, by relatively more, the demand of other factor of production and its income share. For this reason, capital-augmenting productivity innovations tend to favour vacancy creation (and employment) over capital accumulation. Finally, we disentangle the role of factor complementarity, deep habits and HM effect through impulse response analysis and counterfactual exercises.

The paper is organised as follows. Section 2 presents the model. Section 3 discusses the endogenous mechanisms. Section 4 illustrates the estimation strategy, evaluates the quantitative performance of the model and discusses the dynamic properties of the model. The final section concludes. The appendix complements the paper by providing: details on the construction of the dataset, a more detailed explanation of the model, the full set of equilibrium conditions (and their linearised counterparts) and the steady state of the model.

\section{The Model}

The model features labour market frictions, deep habits in private and public consumption, nominal rigidities and a CES production function. Our model economy is inhabited by four

\footnotetext{
${ }^{2}$ These innovations have the following drawbacks: i) price-elasticity innovations are highly controversial because they entail large shifts in the competitive structure of the economy over the short-run (see Chari et al., 2007); and ii) as observed by Rotemberg (2008), the size of the innovations needed to match volatilities is relatively large.

${ }^{3}$ For earlier attempts to estimate a DSGE model featuring a CES production function, see e.g. Cantore et al. (2012).
} 
types of agents: a continuum of households, a continuum of firms, a monetary and a fiscal authority. Households maximise utility and firms profits. The agents in the economy interact in the goods, bonds, capital and labour markets. More details of the model are available in Appendix B.

The labour market is frictional in that firms fill jobs by posting vacancies at a unitary cost, $\kappa_{v}$. The technology that matches jobs with workers is given by

$$
m_{t}=\bar{m}_{t} v_{t}^{\gamma} \tilde{u}_{t}^{1-\gamma}
$$

where $m_{t}$ denotes the aggregate flow of hires at time $t, \tilde{u}_{t}$ denotes job searchers, $v_{t}$ aggregate vacancies and $\bar{m}_{t}$ an innovation to the efficiency of the matching. The parameter $\gamma \in(0,1)$ is the elasticity of the matching function with respect to aggregate vacancies. At time $t$, vacancies are filled with probability $q\left(\theta_{t}\right)=m_{t} / v_{t}=\bar{m}_{t} \theta_{t}^{\gamma-1}$, where $\theta_{t}=v_{t} / \tilde{u}_{t}$ is the measure of labour market tightness. The assumption of constant returns to scale in the matching function implies that workers find jobs with probability $m_{t} / \tilde{u}_{t}=\theta_{t} q\left(\theta_{t}\right)$. Following Ravenna and Walsh (2008), we assume that new hires become immediately productive after being matched to a firm. The law of motion for aggregate employment (denoted by $n_{t}$ ) can be written as

$$
n_{t}=m_{t}+(1-\rho) n_{t-1}
$$

where $\rho$ is the exogenous separation rate. Job searchers are given by

$$
\tilde{u}_{t}=1-(1-\rho) n_{t-1} .
$$

The search rate at time $t$ is given by the unemployment rate at $t-1$, defined as $u_{t}=1-n_{t}$ at time $t$, plus the measure of workers who lost their job at the end of $t-1, \rho n_{t-1}$.

There is a mass of households in the unit interval $j \in[0,1]$ whose members search for jobs if unemployed and work for firms if employed. Employed workers receive a wage payment, denoted by $W_{f t}$, in return for their labour services from firm $f$ and unemployed workers receive unemployment benefits, denoted by $\bar{b}$. Household $j$ maximises her lifetime utility by choosing a consumption object, $\left(x_{t}^{c}\right)^{j}$, nominal bond holdings, $B_{t}^{j}$, physical capital, $k_{t}^{j}$, and investment, $i_{t}^{j}$. The period utility depends positively on a measure of habit-adjusted consumption, negatively on labour supply and is given by

$$
\mathcal{U}\left[\left(x_{t}^{c}\right)^{j}, h_{f t}^{j}, n_{f t}^{j}\right]=\frac{\left[\left(x_{t}^{c}\right)^{j}-\ln \left(z_{c t}\right)\right]^{1-\sigma}-1}{1-\sigma}-\chi \int_{0}^{1} n_{f t}^{j} \frac{\left(h_{f t}^{j}\right)^{1+\varphi}}{1+\varphi} d f,
$$

where $\chi$ is a constant, $\sigma$ denotes the inverse of the inter-temporal elasticity of substitution between the consumption object at time $t$ and $t+1$ and $\varphi$ the inverse of the Frisch elasticity of labour supply. The term $n_{f t}^{j}$ denotes the employment rate and $h_{f t}^{j}$ hours worked by household $j$ at firm $f$. The variable $z_{c t}$ is a preference shock.

Households' preferences (as well as the government's) exhibit external habit formation in consumption at the good-specific level rather than at the aggregate level. Ravn et al. (2006) have coined this consumption externality as deep habits (DH from now on) or, alternatively, as catching-up with the Joneses good by good. Households (and the fiscal authority) demand the different varieties supplied by firms. Each household chooses the individual demands of variety $f$ by minimising expenditure. Adding up the individual households demands, $c_{f t}^{j}$, over $j$, yields the demand for variety $f$

$$
c_{f t}=\left(\frac{P_{f t}}{P_{t}}\right)^{-\epsilon} x_{t}^{c}+\zeta_{c} s_{t-1}^{c},
$$

where

$$
s_{f t}^{c}=\vartheta_{c} s_{f t-1}^{c}+\left(1-\vartheta_{c}\right) c_{f t}
$$


is the law of motion of the habit stock $\left(s_{f t}^{c}\right)$ for each variety,

$$
x_{t}^{c}=\left[\int_{0}^{1}\left(c_{f t}-\zeta_{c} s_{f t-1}^{c}\right)^{1-1 / \epsilon} d f\right]^{1 /(1-1 / \epsilon)}
$$

is the habit adjusted consumption object, $\epsilon$ the intra-temporal elasticity of substitution of habit adjusted consumption across varieties, $P_{f t}$ is the price of variety $f$ and $P_{t}$ the aggregate price level. The parameter $\zeta_{c} \in[0,1)$ denotes the degree of habit formation in private consumption and $\vartheta_{c} \in[0,1)$ the persistence of the habit stock. The minimisation problem of the government is analogous to the problem of each household. The parameters $\zeta_{g}$ and $\vartheta_{g}$ represent the corresponding habitual measures for public consumption. The individual demands for investment of variety $f, i_{f t}$, take the following form

$$
i_{f t}=\left(\frac{P_{f t}}{P_{t}}\right)^{-\epsilon} i_{t}
$$

where $i_{t}$ denotes aggregate investment. The aggregated law of motion of physical capital, $k_{t}$, is

$$
\left[1-\frac{\kappa_{i}}{2}\left(\frac{i_{t}}{i_{t-1}}-1\right)^{2}\right] z_{i t} i_{t}=k_{t}-(1-\delta) k_{t-1},
$$

where $\kappa_{i}$ measures investment adjustment costs and $z_{i t}$ is an investment-specific innovation.

There is a mass of monopolistically competitively firms, defined in the unit interval $f \in[0,1]$, each of which produces a particular variety of the final good. Each variety $f$ is produced using two inputs: labour, $\ell_{f t}=n_{f t} h_{f t}$, and capital, $k_{f t-1}$. While the labour input can vary along the intensive margin, $h_{f t}$, and the extensive margin, $n_{f t}$, physical capital only along the extensive margin. One difference between the two factors of production is their respective adjustment lags: i) hired workers become immediately productive and ii) physical capital adjusts with a lag. Factor adjustment costs differ between labour and capital due to the presence of search and matching frictions, on one hand, and investment adjustment costs, on the other. Following León-Ledesma et al. (2010a), the production function is of the CES form

$$
y_{f t}=\left[\alpha_{k}\left(z_{k t} k_{f t-1}\right)^{\frac{\eta-1}{\eta}}+\alpha_{\ell}\left(z_{\ell t} \ell_{f t}\right)^{\frac{\eta-1}{\eta}}\right]^{\frac{\eta}{\eta-1}}
$$

where the variable $y_{f t}$ denotes the output of firm $f, z_{k t}$ a capital-augmenting technology shock, $z_{\ell t}$ a labour-augmenting technology shock and $\alpha_{k}$ and $\alpha_{\ell}$ the distribution parameters. The CES production function nests the Cobb-Douglas production function when $\eta=1$; the Leontief function (i.e., fixed proportions) when $\eta=0$; and a linear production function (i.e., perfect substitutes) when $\eta \rightarrow \infty$. When $\eta<1$, factors are gross complements in production; factors are gross substitutes otherwise.

Firms face costs related to price adjustment and vacancy posting; these costs are quadratic in the former and linear in the latter. The adjustment cost parameters are denoted by $\kappa_{p}$ and $\kappa_{v}$ for price and vacancy costs respectively. Optimal price setting at the firm level is subject to equations (5) (together with the corresponding demand for public consumption) and (8). The introduction of deep habits changes the pricing incentives of firms and the dynamics of markups $\left(\mu_{f t}\right)$. In the absence of price adjustment costs, firms have the incentive to reduce prices after an expansionary exogenous innovation, which in turn increases current sales and secures higher future sales due to the habitual nature of demand. However, this optimal behaviour is partly restricted by the fact that it is costly for firms to change prices. Appendix B contains an expression that is akin to the Phillips curve, which results from the pricing decision of firms.

We here state the optimal conditions for vacancy creation and detail the derivation of all the other optimality conditions in the appendix. The job creation condition results from combining the optimal condition with respect to vacancies, equation (63), and the marginal value 
of employment, equation (65),

$$
\frac{\kappa_{v}}{q\left(\theta_{t}\right)}=\frac{F_{f t}^{\ell} h_{f t}}{\mu_{f t}}-\frac{W_{f t}}{P_{t}} h_{f t}+\beta(1-\rho) E_{t} \frac{\lambda_{t+1}}{\lambda_{t}} \frac{\kappa_{v}}{q\left(\theta_{t+1}\right)}
$$

where

$$
F_{t}^{\ell}=\left(\frac{y_{t}}{n_{t} h_{t}}\right)^{\frac{1}{\eta}} \alpha_{n}\left(z_{\ell t}\right)^{\frac{\eta-1}{\eta}}
$$

is the marginal product of labour, $\lambda_{t}$ the marginal utility of habit adjusted consumption and $E_{t} \frac{\lambda_{t+1}}{\lambda_{t}}$ the stochastic discount factor. Equation (11) states that firm $f$ will expand employment until the point where marginal costs and benefits are equalised. The job creation condition is at the centre of our analysis and will be investigated further in the following section.

Wages are flexible (negotiated period by period) and determined by maximising the joint surplus of a match following a Nash bargaining protocol. ${ }^{4}$ Without impediments to wage adjustments, the desired split of the surplus is achieved. The solution to the Nash bargaining problem is given by

$$
\xi \mathcal{J}_{f t}=(1-\xi) \mathcal{W}_{f t},
$$

where $\xi$ denotes the nominal bargaining power of the worker and $\mathcal{W}_{f t}$ and $\mathcal{J}_{f t}$ the worker's and firm's surpluses. The real wage is thus

$$
w_{f t} h_{f t}=\xi\left[\frac{F_{f t}^{\ell}}{\mu_{f t}} h_{f t}+\kappa \beta(1-\rho) E_{t} \frac{\lambda_{t+1}}{\lambda_{t}} \theta_{t+1}\right]+(1-\xi)\left[\bar{b}+\chi \frac{h_{f t}^{1+\varphi}}{\lambda_{t}(1+\varphi)}\right] .
$$

The real wage per worker is a function of the marginal revenue product of employment, the opportunity cost of replacing the worker and the opportunity cost of being employed at firm $f$. Hours per workers are decided such that the marginal revenue product of labour equals the marginal rate of substitution,

$$
\frac{F_{f t}^{\ell}}{\mu_{f t}}=\chi \frac{h_{f t}^{\varphi}}{\lambda_{t}}
$$

This condition states that hours worked are independent of the hourly wage.

The dynamics of the model is driven by seven exogenous processes: factor-biased productivity (labour and capital-augmenting), preference, investment-specific, government expenditure, monetary policy and matching efficiency innovations. The processes in the model evolve according to

$$
\ln z_{x t}=\varrho_{x} \ln z_{x t-1}+\varepsilon_{x t} \quad \text { with } \quad \varepsilon_{c t} \sim N\left(0, \varsigma_{x}\right) \quad \text { for } \quad x=\{c, i, g, k, \ell, m\},
$$

where $\varrho_{x}$ is the persistence of the shock and $\varsigma_{x}$ the standard deviation of the innovation $\varepsilon_{x t}$. Note that $z_{g t}=g_{t}$ and $z_{m t}=\bar{m}_{t}$.

We assume symmetry across firms and households. The monetary authority is assumed to set the nominal interest rate $R_{t}$ following a Taylor rule of the form:

$$
\frac{R_{t}}{R}=\left(\frac{R_{t}}{R}\right)^{r_{r}}\left[\left(\frac{\pi_{t}}{\pi}\right)^{r_{\pi}}\left(\frac{y_{t}}{y_{t-1}}\right)^{r_{y}}\right]^{1-r_{r}} \exp \left(\varepsilon_{r t}\right), \quad \text { with } \quad \varepsilon_{r t} \sim N\left(0, \varsigma_{r}\right),
$$

where $r_{r} \in(0,1)$ captures the degree of inertia and $r_{\pi}>0$ and $r_{y}>0$. In addition, the government budget constraint is given by

$$
g_{t}+\left(1-n_{t}\right) \bar{b}+\frac{R_{t-1}}{P_{t}} B_{t-1}=\frac{B_{t}}{P_{t}}+\bar{\tau}_{t},
$$

\footnotetext{
${ }^{4}$ We did however attempt to introduce wage rigidities into our framework and were unable to identify the wage rigidity parameter, even after introducing the wage rate as an observable variable.
} 
where $\bar{\tau}_{t}$ are the aggregated lump-sum taxes paid by households. Finally, market clearing in the goods market is given by

$$
y_{t}=c_{t}+g_{t}+i_{t}+\kappa_{v} v_{t}+\mathcal{A}_{t}
$$

This condition states that aggregate output is consumed, invested and also used to pay for both vacancy costs, $\kappa_{v} v_{t}$, and price adjustment costs, $\mathcal{A}_{t}$.

\section{Transmission Mechanisms}

This section studies the exogenous and endogenous sources of amplification in the model. We first examine the role of factor-biased productivity innovations as potential exogenous mechanisms within the context of a CES production function. We then focus the analysis on the remaining two endogenous sources of amplification: deep habits and unemployment benefits.

\subsection{CES and Factor-Biased Productivity Innovations}

Here we show that factor-biased productivity innovations affect output directly and indirectly through factor demands. We argue that these effects depend on the source of the innovation and the degree of substitutability between factors.

Log-linearising equation (10) yields the following expression ${ }^{5}$

$$
\widehat{y}_{t}=\alpha_{k}\left(\frac{z_{k} \bar{k}}{\bar{y}}\right)^{\eta-1} \eta\left(\widehat{z}_{k t}+\widehat{k}_{t-1}\right)+\alpha_{k}\left(\frac{z_{\ell} \bar{n} \bar{h}}{\bar{y}}\right)^{\eta-1} \eta\left(\widehat{z}_{\ell t}+\widehat{n}_{t}+\widehat{h}_{t}\right) .
$$

Since $\eta>0$ and the steady state values of capital, labour and output are positive, it follows that factor-biased productivity innovations must increase output. It can be shown, however, that the direct response to factor-biased productivity innovations varies with the value of $\eta$. Differentiating equation (20) with respect to each of the factor-biased productivity innovations and then with respect to $\eta$ yields

$$
\frac{\partial^{2} \widehat{y}_{t}}{\partial \widehat{z}_{k t} \partial \eta}=\alpha_{k}\left(\frac{z_{k} \bar{k}}{\bar{y}}\right)^{\eta-1}\left[1+\eta \log \left(\frac{z_{k} \bar{k}}{\bar{y}}\right)\right]
$$

and

$$
\frac{\partial^{2} \widehat{y}_{t}}{\partial \widehat{z}_{\ell t} \partial \eta}=\alpha_{\ell}\left(\frac{z_{\ell} \bar{n} \bar{h}}{\bar{y}}\right)^{\eta-1}\left[1+\eta \log \left(\frac{z_{\ell} \bar{n} \bar{h}}{\bar{y}}\right)\right] .
$$

These expressions show the extent to which the response to output after factor-biased productivity innovations is affected by the value of $\eta$. In particular, there exists a cut-off value of $\eta$ for which the responses of output change in magnitude. Note that the capital to income ratio in the steady state is generally greater than unity and that the labour to income ratio generally lower. The magnitude of the responses is given by the dimension factors $\left(\alpha_{k}\right.$ and $\left.\alpha_{\ell}\right)$, which in turn depend on the calibration of the factor shares and the elasticity of substitution. Under gross complementarity $(\eta<1)$, labour-augmenting productivity innovations have a larger direct impact on output because the ratio of output to labour, i.e. $\frac{\bar{y}}{z_{\ell} \bar{n} h}$, is greater than unity and the absolute value of $\eta \log \left(\frac{z_{k} \bar{n} \bar{h}}{\bar{y}}\right)$ is smaller. ${ }^{6}$ Thus, the direct impact on output arising from labour-augmenting productivity innovations is larger under gross factor complementarity and smaller under gross factor substitutability. Capital-augmenting productivity innovations tend to increase output and the magnitude of the increment is a function of $\eta$. Keeping everything

\footnotetext{
${ }^{5} \mathrm{~A}$ hat over a variable indicates the log-deviation from the variables' steady state value, while a bar indicates the steady state value.

${ }^{6}$ Note that $(n h / y)^{\eta-1}$ is greater when $\eta<1$ compared to the case of gross substitutability $(\eta>1)$ when labour-augmenting productivity innovations have a smaller direct impact on output.
} 
else constant, the larger $\eta$, the greater the impact on output. This means that the direct impact on output after capital-augmenting productivity innovations is larger under gross factor substitutability and smaller under gross factor complementarity.

Productivity innovations affect factor demands differently, which in turn have an indirect impact on output. The response of factor demands to these innvations also depends on $\eta$. To see this, we first log-linearise the marginal products of capital and labour and obtain the following expressions

$$
\widehat{F}_{t}^{\ell}=\frac{1}{\eta}\left(\widehat{y}_{t}-\widehat{n}_{t}-\widehat{h}_{t}\right)+\frac{\eta-1}{\eta} \widehat{z}_{\ell t}
$$

and

$$
\widehat{F}_{t}^{k}=\frac{1}{\eta}\left(\widehat{y}_{t}-\widehat{k}_{t-1}\right)+\frac{\eta-1}{\eta} \widehat{z}_{k t} .
$$

We substitute $\widehat{y}_{t}$ into (23) and (24) such that

$$
\widehat{F}_{t}^{\ell}=\left[\alpha_{n}\left(\frac{\bar{z}_{\ell} \bar{n} \bar{h}}{\bar{y}}\right)^{\eta-1}\left(\widehat{z}_{\ell t}+\widehat{n}_{t}+\widehat{h}_{t}\right)+\alpha_{k}\left(\frac{\bar{z}_{\ell} \bar{k}}{\bar{y}}\right)^{\eta-1}\left(\widehat{z}_{k t}+\widehat{k}_{t-1}\right)-\frac{1}{\eta}\left(\widehat{n}_{t}+\widehat{h}_{t}\right)\right]+\frac{\eta-1}{\eta} z_{\ell t}
$$

and

$$
\widehat{F}_{t}^{k}=\left[\alpha_{n}\left(\frac{\bar{z}_{\ell} \bar{n} \bar{h}}{\bar{y}}\right)^{\eta-1}\left(\widehat{z}_{\ell t}+\widehat{n}_{t}+\widehat{h}_{t}\right)+\alpha_{k}\left(\frac{\bar{z}_{\ell} \bar{k}}{\bar{y}}\right)^{\eta-1}\left(\widehat{z}_{k t}+\widehat{k}_{t-1}\right)-\frac{1}{\eta} \widehat{k}_{t-1}\right]+\frac{\eta-1}{\eta} z_{k t} .
$$

Differentiating the marginal products with respect to the innovations yields the following partial derivatives

$$
\begin{gathered}
\frac{\partial \widehat{F}_{t}^{\ell}}{\partial z_{\ell t}}=\alpha_{n}\left(\frac{\bar{z}_{\ell} \bar{n} \bar{h}}{\bar{y}}\right)^{\eta-1}+\frac{\eta-1}{\eta} \\
\frac{\partial \widehat{F}_{t}^{\ell}}{\partial z_{k t}}=\alpha_{k}\left(\frac{\bar{z}_{\ell} \bar{k}}{\bar{y}}\right)^{\eta-1}, \\
\frac{\partial \widehat{F}_{t}^{k}}{\partial z_{\ell t}}=\alpha_{n}\left(\frac{\bar{z}_{\ell} \bar{n} \bar{h}}{\bar{y}}\right)^{\eta-1}
\end{gathered}
$$

and

$$
\frac{\partial \widehat{F}_{t}^{k}}{\partial z_{k t}}=\alpha_{k}\left(\frac{\bar{z}_{\ell} \bar{k}}{\bar{y}}\right)^{\eta-1}+\frac{\eta-1}{\eta} .
$$

To understand the extent to which $\eta$ determines the shifts in factor demands after a labouraugmenting productivity innovation, we compare $\frac{\partial \widehat{F}_{t}^{\ell}}{\partial z_{\ell t}}$ and $\frac{\partial \widehat{F}_{t}^{k}}{\partial z_{\ell t}}$ and derive the following condition

$$
\alpha_{n}\left(\frac{\bar{z}_{\ell} \bar{n} \bar{h}}{\bar{y}}\right)^{\eta-1}+\frac{\eta-1}{\eta}>\alpha_{k}\left(\frac{\bar{z}_{\ell} \bar{n} \bar{h}}{\bar{y}}\right)^{\eta-1} \Rightarrow \eta-1>0 \Rightarrow \eta>1 .
$$

A similar logic follows from comparing the responses of the marginal products to capitalaugmenting productivity innovations. The general finding is that a $J$-augmenting productivity innovation favours the $J$ factor under gross substitutability and the demand of factor $I$ under gross complementarity (see also León-Ledesma et al., 2010a). An expansionary capitalaugmenting productivity innovation, thus, increases labour demand by more than the demand for capital when factors are gross complements. This implies that capital-augmenting productivity innovations can have a large effect on vacancy creation. Hence, an expansionary capitalaugmenting productivity innovation favours labour demand under gross factor complementarity but tends to reduce the size of the direct impact on output. 


\subsection{Mark-ups, DH and HM effect}

We examine the behaviour of mark-ups through investigating some of the key features of the model: nominal price rigidities, the CES production function and search and matching frictions. We then explore the interaction between mark-ups and the deep habit mechanism to explain part of the amplification that is generated in the model. We conclude the section by discussing the role of unemployment benefits as a potential source of amplification.

Galí (1999) shows that, in the presence of nominal price rigidities, mark-ups tend to increase after neutral productivity innovations but to decrease after demand-side innovations in the standard New Keynesian (NK) model. This feature of the NK model still holds under more general production functions such as the CES. However, the value of $\eta$ has a very important effect on the behaviour of mark-ups. Abstracting from search frictions, mark-ups can be expressed as the ratio of marginal products to factor payments. Substituting for the marginal products using equations (67) and (64) yields the following expressions for mark-ups

$$
\mu_{t}=\frac{F_{t}^{\ell}}{w_{t}^{W}}=\alpha_{\ell}\left(\frac{z_{\ell t}}{w_{t}^{W}}\right)^{\frac{\eta-1}{\eta}}\left(\frac{y_{t}}{w_{t} n_{t} h_{t}}\right)^{\frac{1}{\eta}}=\frac{F_{t}^{k}}{r_{k t}}=\alpha_{k}\left(\frac{z_{k t}}{r_{t}}\right)^{\frac{\eta-1}{\eta}}\left(\frac{y_{t}}{r_{t} k_{t-1}}\right)^{\frac{1}{\eta}} .
$$

where $w_{t}^{W}$ denotes the Walrasian wage rate. Under the Cobb-Douglas case $(\eta=1)$, it is easy to show that mark-ups can be approximated by the factor shares. This is, however, no longer the case under the CES production function. The response of mark-ups after factor-bias productivity innovations is less pro-cyclical under factor complementarity than substitutability.

Replacing the wage rate into the job creation condition, equation (11), yields an expression for mark-ups that can be written in terms of the marginal productivity of labour, $F_{t}^{\ell}$ and a measure of labour market adjustments $\Gamma_{t}$

$$
\mu_{t}=\frac{F_{t}^{\ell}}{\Gamma_{t}}
$$

where

$$
\Gamma_{t}=\frac{1}{h_{t}}\left\{b+\chi \frac{h^{1+\varphi}}{(1+\varphi) \lambda_{t}}+\frac{\kappa}{q\left(\theta_{t}\right)}+\beta(1-\rho) E_{t} \frac{\lambda_{t+1}}{\lambda_{t}}\left[\frac{\epsilon}{1-\epsilon} \kappa \theta_{t+1}-\frac{\kappa}{q\left(\theta_{t+1}\right)}\right]\right\} .
$$

Mark-ups are thus equal to the ratio between the marginal product of labour and $\Gamma_{t}$, which can be understood as the corresponding measure of the wage rate in the frictionless model. The wage is not equal to the marginal rate of substitution but depends on the measure of labour market tightness. Keeping everything equal, there is a negative relationship between mark-ups and the measure of labour market tightness. An increase in $\theta_{t}$ tends to have a positive impact on $\Gamma_{t}$, which in turn reduces mark-ups (and viceversa). Therefore, the model featuring frictions requires a mechanism able to generate counter-cyclical mark-up fluctuations to increase the firms' incentives for vacancy creation.

Absent nominal rigidities, the DH mechanism is able to generate a fall in mark-ups after a wide range of innovations. Note that, following an expansionary factor-biased productivity innovation, both DH and factor complementarity tend to push the measure of mark-ups downwards. The presence of DH affects the supply side of the model, the pricing decision of firms and the behaviour of mark-ups. The optimal behaviour of mark-ups under DH is guided by the following expression

$$
\mu_{t}=\frac{1}{1-\nu_{t}+(1-\vartheta) \psi_{t}} .
$$

Hence, a fall in mark-ups is due to an increase in the price elasticity of demand, equivalent to a fall in $\nu_{t}$, and to a rise in the value of future customer relationships, through a higher shadow value of the habit stock, $\psi_{t}$. After an expansionary technological innovation, firms have 
an incentive to lower prices and to hire more worker to satisfy a higher demand for goods. As shown in Di Pace and Faccini (2012), the higher the values of $\zeta$ and $\vartheta$ the higher the incentive for vacancy creation.

However, nominal price rigidities constrain the optimal pricing behaviour of firms under deep habits. The pro-cyclicality of mark-ups after productivity innovations tends to dampen job creation as the marginal revenue product of employment falls. The DH mechanism reinforces the fall in hiring after an expansionary labour-augmenting productivity innovation but dampens the rise in job creation following an expansionary capital-augmenting productivity innovation. Present nominal rigidities, this mechanism can help explain large part of the variation in labour market variables through demand-side innovations because they generate counter-cyclical markup fluctuations.

The HM strategy consists of setting the value of non-employment utility close to the market productivity and a very low value of the workers' bargaining power. i.e., a low $\gamma$ and high total replacement ratio, defined as $\bar{b} / w h+\chi h^{(1+\varphi)} /[\lambda(1+\varphi)] / w h$ in the steady state. The total replacement ratio is increasing in unemployment benefits $(\bar{b})$ and decreasing in the degree of habit formation in consumption. The DH mechanism and the HM effect act as competing forces. A rise in $\bar{b}$ increases the outside option of employment to the worker, which in turn raises the value of wages and lowers the value of profits per hire in the steady state. Less persistence in consumption leads to a rise in the disutility of work and the outside option of the worker. Profits per hire tend to be more sensitive to innovations when the profits are small, resulting in higher volatility of labour market variables over the cycle.

\section{Model Estimation - Results}

This section presents the results of the Bayesian estimation. Section 4.1 discusses the calibration and estimation of the structural parameters. Section 4.2 compares the model implied volatilities with those in the data and presents a counterfactual exercise to assess the endogenous sources of amplification. Section 4.3 is dedicated to the study of the impulse responses functions.

\subsection{Estimation Strategy}

Following An and Schorfheide (2007), the model is estimated using Bayesian methods for the US economy over the Great Moderation (1984Q1-2007Q4). We focus on this period because it is characterised by a single and unified monetary policy regime. We choose the following data as the observable variables in our model: GDP, investment, consumption, vacancies, the unemployment rate, the inflation rate and the federal funds rate. Appendix A gives a detailed discussion of data sources, definitions, data transformations and estimation strategy.

Our estimation and calibration strategy follows closely the procedure proposed by Smets and Wouters (2007). We calibrate some parameters to match key stylised facts in the labour market and estimate the remaining parameters. The data series used as observable variables are chosen to add informational content for estimating the posterior distributions of the parameters of interest. The locations of the prior means correspond to a large extent to those in previous studies carried out on the US economy, e.g. Smets and Wouters (2007). The prior distributions of the parameters are shown in Table 2 .

The time period in the model corresponds to one quarter in the data. The discount factor, $\beta$, is set equal to 0.99 , implying a quarterly real interest rate of $1 \%$. The depreciation rate of capital, $\delta$, is set equal to 0.025 . In line with the literature, we set the elasticity of substitution of habit adjusted consumption to 6 . The value of the Frisch elasticity of labour supply, $1 / \varphi$, is a source of controversy in the literature. While most microeconomic studies suggest an estimate of the elasticity ranging from 0 to 0.5 , the estimates used by the business cycle literature are 
much higher. ${ }^{7}$ We choose an intermediate value of $\varphi$ equal to 5 . This choice implies that output adjusts relatively more over the extensive labour margin, being in line with a wide range of empirical findings. Finally, we calibrate the great ratios in line with the data, as shown in Table 1 .

Following the approach taken by Furlanetto and Groshenny (2013), we set the unemployment rate and the job filling rate equal to their long-run targets, $6 \%$ and $70 \%$ respectively. The parameter $\xi$ is chosen to pin down the long-run target of the unemployment rate. We normalise the steady state value of hours worked to 0.33. In line with den Haan et al. (2000), we set the vacancy-filling rate to its long-run target and recover the matching efficiency parameter, $\bar{m}$, that attains this target. We set the ratio of vacancies to GDP to 0.01 , a value that is consistent with Gertler and Trigari (2009) and Blanchard and Gali (2010).

The posterior mean estimates of DH and unemployment benefits are statistically significantly different from zero as evident from Table 2. The DH estimates in private consumption are very close to those of Ravn et al. (2006); the posterior mean estimate of the degree of $\mathrm{DH}$ is 0.86 and that of habit persistence 0.86. The degree and persistence of $\mathrm{DH}$ in public consumption are lower than in the literature, 0.46 and 0.49 respectively. The posterior mean estimate of the income replacement ratio is 0.61 , which in turn corresponds to a total income replacement ratio of $0.78 \%$. This estimate is line with the standard value of $70 \%$ as suggested in Mortensen and Nagypal (2007). Moreover, we find strong support for gross factor complementarity in the production process. In line with León-Ledesma et al. (2010a,b), the posterior mean of the elasticity substitution is significantly lower than unity, $\eta=0.18$. The implied value of the steady state labour share is reasonable and equal to 0.78 . Hence, the data tends to agree with the frictions introduced in the model, which in turn can be thought of possible endogenous mechanisms of amplification.

The posterior mean of the price adjustment cost is 51.89, which implies that firms adjust prices almost every year. The monetary authority responds aggressively to inflation and output growth, with estimated coefficients $r_{\pi}$ and $r_{y}$ equal to 3.16 and 0.45 . A Taylor rule that targets output growth is not only consistent with the DH model but it also helps circumvent determinacy problems present in models featuring search and matching frictions, nominal price rigidities and $\mathrm{DH}^{8}{ }^{3}$ This rule is highly inertial during the period under consideration, with an estimated interest rate smoothing parameter of 0.85 .

The government spending shock and, to a minor extent, the two productivity innovations are highly persistent. The standard deviation of the monetary policy shocks is relatively low and the dispersion of investment-specific shocks high. An advantage of our approach is that the size of innovations needed to explain fluctuations in labour market variables is lower than the estimates found in studies featuring other sources of exogenous fluctuations such as price-elasticity shocks (see Rotemberg, 2008; Krause et al., 2008).

\subsection{Sources of Amplification}

Table 3 reports the statistical properties of output, investment and labour market variables in the US data over the period of the Great Moderation. We compare actual against simulated data and then shut down the various endogenous mechanisms to assess their importance. To make an appropriate comparison with the estimated model, we detrend both macroeconomic aggregates and labour market variables using a common linear trend (as our estimation procedure assumes a linear trend in the data). We find that unemployment and vacancies are about 9 times and 10.6 times more volatile than output in the data.

Table 3 shows that our model can replicate the data reasonably well in terms of the relative dispersions of labour market variables, employment, unemployment and vacancies $\left(\hat{n}_{t}, \hat{u}_{t}\right.$ and $\hat{v}_{t}$

\footnotetext{
${ }^{7}$ For a survey of the literature see Card (1991).

${ }^{8}$ See Kurozumi and Van Zandweghe (2010).
} 
respectively). However, our model is less successful at matching the relative standard deviation of investment $\left(\hat{i}_{t}\right)$. The latter result can be attributed partly to the high factor complementarity between labour and capital and partly to the absence of well structured capital markets. The baseline model is successful at reproducing the autocorrelations observed in the data. As far as output correlations are concerned, the model predicts a stronger co-movement between employment and output; a finding that is also present in Di Pace and Faccini (2012). The correlation between vacancies and output is broadly in line with the data but the model is less successful at replicating the co-movement between investment and output.

A counterfactual exercise is performed to assess the extent to which the three endogenous mechanisms matter for amplification. We present three alternative specifications: (1) a model featuring a Cobb-Douglas (CD) production function, DH and the HM effect to examine the importance of the estimated factor complementarity; (2) a model featuring a CES production function and the HM effect but excluding DH to analyse the latter mechanism in isolation; and (3) a model exhibiting a CES production function but without DH and HM to understand the role of factor complementarity on its own.

Table 3 shows that, keeping the long-run targets and estimates of the other parameters constant, factor complementarity plays an important role in replicating the volatilities of labour market variables. The absence of such mechanism reduces by about a half the relative volatilities of unemployment and vacancy (to 4.35 and 4.92 respectively). As discussed in Section 3.1, expansionary capital-augmenting technology innovations increase labour demand under gross factor complementarity, which in turn leads to more vacancy creation. The counterfactual model with a CD production function is less successful in matching the first order autocorrelations with the data, and predicts a stronger correlation between output and labour market variables.

Removing the DH mechanism from the baseline model (by setting the degree of habits to zero) reduces the volatility of labour market variables by about a third in relation to the baseline model and also worsens the autocorrelations of vacancies in relation to the data. The DH mechanism helps improve the dynamics of labour market variables by generating hump-shaped responses in output, consumption, unemployment and vacancies. We find that shutting down DH and HM (by reducing the income replacement ratio to 0.40 , while its estimated value is equal to 0.61 ) reduces the amplification of vacancies and unemployment relative to the baseline model by around $50 \%$ and $60 \%$ respectively. The DH mechanism and HM effect worsen, if anything, the correlations between employment/unemployment and output. Our counterfactual analysis shows that, although all three endogenous mechanisms are important, factor complementarity explains a larger part of the amplification in labour market variables.

To assess the importance of the exogenous mechanisms of amplification, we conduct a variance decomposition analysis. Table 4 shows that capital-augmenting innovations are crucial to explain fluctuations in unemployment. This follows from the fact that capital-augmenting technology innovations generate output correlations that are in line with the data (as shown in Figure 1 and discussed in the following section). Over shorter horizons, the variance of unemployment can be explained mainly by investment-specific and matching efficiency innovations. After four years, capital-augmenting productivity innovations become the single most important source of variation, accounting for about $35 \%$ of the fluctuations in unemployment. This proportion increases to $55 \%$ after 5 years to then falls to about $50 \%$ after 10 years. Investment-specific innovations are non-negligible, helping to explain around $17 \%$ of the unconditional variance of unemployment. The explanatory power of investment-specific innovations on the variance of labour market variables can be ascribed to the high estimated factor complementarity, which generates a tight link between the factors of production.

Similarly to unemployment, fluctuations in both vacancies and wages are mainly driven by capital-augmenting technology shocks, with investment-specific shocks playing a major role over shorter horizons. Table 4 shows that, while demand-side innovations explain a significant part of output variation in the very short term, capital and labour-augmenting innovations are key 
driving forces over longer horizons, accounting for about $67 \%$ of output variation. This result is broadly in line with the findings of McAdam and Willman (2013). Regarding fluctuations in mark-ups, while the importance of factor-biased technology innovations falls over time, the role of demand-side innovations increases over time, explaining more than $50 \%$ of unconditional variation. In addition, we find that demand-side shocks explain a significant part of the variation in output and labour market variables over shorter horizons and that factor-biased productivity innovations are relatively more relevant over the medium to long term. This pattern is reversed for mark-ups.

In sum, the interaction between the endogenous and exogenous amplification mechanisms is key for explaining the volatility of labour market variables present in the data. Capitalaugmenting productivity shocks dominate over the other sources of exogenous fluctuations for explaining labour market amplification because of gross factor complementarity. Moreover, demand shocks are important exogenous sources of fluctuations over shorter horizons because the demand side of the model is augmented for deep habits. The DH mechanism is, however, restricted by the presence of price stickiness. Finally, the HM effect interacts with both supply and demand shocks, given that it changes the size of steady state profits per hire.

\subsection{Impulse Responses}

This section examines the impulse responses of output, investment, mark-ups and labour market variables to the innovations in the model. All the simulated innovations are assumed to be expansionary and normalised to one standard deviation.

Figures 1, 2 and 4 show that supply-side innovations (capital-augmenting, labour-augmenting technology and matching efficiency shocks) have a positive impact on mark-ups and output, which in turn reduces inflation. The monetary authority responds to a fall in inflation by lowering the nominal interest rate. This causes a reduction in the real interest rate and an increase in aggregate demand. As productivity increases, less labour is needed to satisfy the increase in demand (see Galí, 1999; Pesavento and Rossi, 2005). The qualitative response of unemployment and vacancies to the two factor-biased technological innovations is, however, strikingly different. Key to the understanding of labour market dynamics under a CES production technology is the response of the marginal productivity of the factors of production. The marginal product of capital, equation (24), falls after a capital-augmenting technology innovation (due to the increase in capital), which in turn reduces the rental rate of capital. Figure 1 shows that the marginal product of labour, together with the wage rate, increase in spite of the fall in labour. Capital-augmenting productivity innovations tend to shift the labour demand schedule upwards, leading to more vacancy creation and higher employment. Under factor complementarity, capital-augmenting technology innovations "favour" the demand for labour, whose factor share rises as evident in Figure 3.

Figure 2 shows the impulse responses of the same variables to a labour-augmenting technology innovation. Hours and employment fall after a labour-augmenting productivity shock. ${ }^{9}$ Thus, firms reduce hiring because the marginal product of employment tends to fall. The increase in mark-ups entails a contraction in the marginal revenue product of employment, reducing even further profits per hire and vacancy creation. While the measure of labour market tightness falls, the job filling rate increases sharply. A contraction in hiring, thus, results in higher unemployment. As a result of the strong gross factor complementarity, Figure 3 shows that the labour share falls in the wake of an expansionary labour-augmenting technology innovation.

Matching efficiency innovations rise the job finding and job filling rates. As depicted in Figure 4 , unemployment falls by more than vacancies, which in turn increases the measure of labour

\footnotetext{
${ }^{9}$ This evidence is consistent with the prediction of the New Keynesian (NK) model but in stark contrast to a conventional real business cycle model. Christiano et al. (2004) provides, however, empirical support against Galí (1999)'s hypothesis that TFP innovations reduce total hours. Our finding is line with recent studies by Balleer (2012) and Canova et al. (2013), which show that employment falls after expansionary TFP innovations.
} 
market tightness. Notwithstanding this, the job filling rate goes up due to a higher efficiency in the matching process. The marginal cost of hiring falls, generating more employment in spite of a fall in vacancies. The increase in employment is partially offset by the fall in hours (and in the marginal rate of substitution between habit adjusted consumption and labour).

Since the transmission mechanism is qualitatively similar under the various demand-side innovations (investment-specific, preference, monetary and government spending shocks), we give a general description of the responses of the variables of interest (shown in Figures 5-8). In models featuring nominal price rigidities, demand-side innovations tend to increase prices and reduce mark-ups. This behaviour of mark-ups is matched by a rise in the wage rate. The fall in mark-ups leads to a higher marginal revenue product of labour, a higher marginal rate of substitution and more hours worked. Lower mark-ups raise the marginal revenue product of employment, which in turn leads to further incentive for vacancy posting. More hiring and, hence, more employment is needed to satisfy the rise in aggregate demand. Higher factor (and aggregate) demands push up factor prices (and inflation). The monetary authority responds to these shifts in aggregate demand by increasing the nominal interest rate more than one-toone to inflation. Demand-side innovations, however, change the composition of expenditure, leading to the crowding-out of some of the components of aggregate demand; i.e., investment is crowded-out after an expansionary government expenditure shock.

We now conduct a counterfactual analysis to compare the amplification mechanism of the baseline model against that of alternative specifications in which the key features of the baseline model are removed one at a time. Figures 9 and 10 show the impulse responses to the most relevant supply-side and demand-side innovations of four alternative specifications: (1) the baseline model, featuring factor complementarity, DH, HM and price stickiness; (2) a counterfactual model with a Cobb-Douglas (CD) production function $(\eta \rightarrow 1)$; (3) a counterfactual model without DH; and (4) the flexible price version of the baseline model.

Three main results emerge. First, factor complementarity plays a key role for explaining labour market outcomes. Contrary to the predictions of the baseline model, capital-augmenting productivity innovations under the CD specification lead to a contraction in vacancy posting (and in employment). Labour-augmenting innovations generate a fall in employment under both the CD and CES model specifications. This means that the combination of capital-augmenting innovations and factor complementarity helps better explain the dynamics of labour market variables. As far as demand-side innovations are concerned, while preference and government expenditure shocks generate more vacancy creation under the CD specification, the combination of factor complementarity and investment-specific innovations are more conducive to vacancy creation under the baseline model. This outcome follows from the fact that investment-specific productivity innovations increase the demand for capital and, as a result of factor complementarity, the demand for employment.

Second, Figure 10 shows that the amplification mechanism induced by DH becomes stronger after demand-side innovations because of the behaviour in mark-ups. In particular, preference and investment-specific innovations lead to stronger counter-cyclicality in mark-ups when compared to the government spending shock. And, as a result, more vacancies are posted.

Third, absent price rigidities, supply-side shocks tend to increase vacancy creation and demand-side innovations to reduce it. If prices were flexible, mark-ups would fall after an expansionary capital-augmenting technology innovation. This would lead to further incentives for vacancy posting because of the increase in the marginal revenue product of employment. Therefore, the deep habits mechanism would strengthen the mechanism of amplification resulting from strong factor complementarity. Removing nominal price rigidities would also imply more vacancy creation after a labour-augmenting technology shock (although this effect would be quantitatively much smaller when compared to capital-augmenting technology innovations). The response of mark-ups to demand-side innovations tends to be counter-cyclical when prices are flexible. Hence, the presence of price rigidities does not alter much the responses of labour 
market variable to demand-side innovations. However, while investment-specific innovations generate pro-cyclical mark-ups fluctuations (investment is not subject to habit formation), government spending innovations generate little variation in mark-ups (habit parameters in public consumption are relatively low). Nominal price rigidities introduce a clear distinction between supply-side and demand-side innovations in terms of the effects of mark-ups on vacancy creation. Except for investment-specific and government spending innovations, all the other expansionary innovations tend to generate a fall in mark-ups, which in turn favours the DH mechanism.

\section{Conclusions}

We assess the role of both endogenous and exogenous sources of amplification for explaining the volatility of the labour market variables. Our DSGE model is able to match the cyclical properties of unemployment and vacancies observed in US data thanks to the empirical relevance of three endogenous mechanisms of amplification: factor complementarity, deep habit formation and a high replacement ratio. We show that the presence of these mechanisms help to match the dynamics of labour market variables and to generate persistent responses of vacancies to a wide set of innovations. The strong factor complementarity that results from our estimations implies that factor-biased innovations tend to shift the demand of the factor complement. Our findings challenge the use of conventional production technologies, such as the Cobb-Douglas production function, in conjunction with TFP innovations.

As far as the exogenous sources of amplification are concerned, we first find that labouraugmenting productivity shocks play an important role at explaining the variation in labour market variables over the very short term. Second, capital-augmenting productivity innovations explain large part of the exogenous variation in labour market variables over the medium and long term. Third, demand-side shocks are relevant sources of amplification since they generate counter-cyclical mark-up fluctuations that tend to reinforce the deep habits mechanism.

\section{References}

Alves, S. A. L. (2012). Trend inflation and the unemployment volatility puzzle. Working Papers Series 277, Central Bank of Brazil, Research Department.

An, S. and Schorfheide, F. (2007). Bayesian analysis of DSGE models. Econometric Reviews, $26(2-4): 113-172$.

Andolfatto, D. (1996). Business cycles and labor-market search. American Economic Review, 86(1):112-32.

Balleer, A. (2012). New evidence, old puzzles: technology shocks and labor market fluctuations. Quantitative Economics, 3(3):363-392.

Barnichon, R. (2010). Building a composite help-wanted index. Economics Letters, 109(3):175178.

Blanchard, O. and Gali, J. (2010). Labor markets and monetary policy: A New Keynesian model with unemployment. American Economic Journal: Macroeconomics, 2(2):1-30.

Canova, F., Lopez-Salido, D., and Michelacci, C. (2013). The ins and outs of unemployment: an analysis conditional on technology shocks. Economic Journal, 123(569):515-539.

Cantore, C., Ferroni, F., and Leon-Ledesma, M. A. (2012). The dynamics of hours worked and technology. Banco de Espana Working Papers 1238, Banco de Espana. 
Cantore, C. and Levine, P. (2012). Getting normalization right: Dealing with 'dimensional constants' in macroeconomics. Journal of Economic Dynamics and Control, 36(12):19311949 .

Cantore, C., Levine, P., and Melina, G. (2014). A fiscal stimulus and jobless recovery. Scandinavian Journal of Economics. Forthcoming.

Card, D. (1991). Intertemporal labor supply: An assessment. NBER Working Papers 3602, National Bureau of Economic Research, Inc.

Chari, V. V., Kehoe, P. J., and McGrattan, E. R. (2007). Business cycle accounting. Econometrica, $75(3): 781-836$.

Choi, S. and Ríos-Rull, J.-V. (2009). Understanding the dynamics of the labor share: the role of non-competitive factor prices. Annales d'Economie et de Statistique, (95-96):251-277.

Christiano, L., Eichenbaum, M., and Vigfusson, R. (2004). The response of hours to a technology shock: Evidence based on direct measures of technology. Journal of the European Economic Association, 2(2-3):381-395.

Christoffel, K. and Kuester, K. (2008). Resuscitating the wage channel in models with unemployment fluctuations. Journal of Monetary Economics, 55(5):865-887.

Costain, J. S. and Reiter, M. (2008). Business cycles, unemployment insurance, and the calibration of matching models. Journal of Economic Dynamics and Control, 32(4):1,120-55.

den Haan, W. J., Ramey, G., and Watson, J. (2000). Job destruction and the experiences of displaced workers. Carnegie-Rochester Conference Series on Public Policy, 52(1):87-128.

Di Pace, F. and Faccini, R. (2012). Deep habits and the cyclical behaviour of equilibrium unemployment and vacancies. Journal of Economic Dynamics and Control, 36(2):183-200.

Faccini, R. and Ortigueira, S. (2010). Labor-market volatility in the search-and-matching model: The role of investment-specific technology shocks. Journal of Economic Dynamics and Control, 34(8):1509-1527.

Fujita, S. and Ramey, G. (2007). Job matching and propagation. Journal of Economic Dynamics and Control, 31(11):3,671-98.

Furlanetto, F. and Groshenny, N. (2013). Mismatch shocks and unemployment during the Great Recession. Working Paper 2013/16, Norges Bank.

Galí, J. (1999). Technology, employment, and the business cycle; do technology shocks explain aggregate fluctuations? The American Economic Review, 89(1):249-271.

Gertler, M., Huckfeldt, C., and Trigari, A. (2014). Unemployment Fluctuations, Match Quality, and the Wage Cyclicality of New Hires. Technical report.

Gertler, M., Sala, L., and Trigari, A. (2008). An estimated monetary DSGE model with unemployment and staggered nominal wage bargaining. Journal of Money, Credit and Banking, 40(8):1,713-64.

Gertler, M. and Trigari, A. (2009). Unemployment fluctuations with staggered Nash wage bargaining. Journal of Political Economy, 117(1):38-86.

Gomes, P. (2011). Fiscal policy and the labour market: the effects of public sector employment and wages. European Economy - Economic Papers 439, Directorate General Economic and Monetary Affairs (DG ECFIN), European Commission. 
Guerrieri, V. (2008). Heterogeneity, job creation and unemployment volatility. Scandinavian Journal of Economics, 109(4):667-693.

Haefke, C., Sonntag, M., and van Rens, T. (2013). Wage rigidity and job creation. Journal of monetary economics, 60(8):887-899.

Hagedorn, M. and Manovskii, I. (2008). The cyclical behavior of equilibrium unemployment and vacancies revisited. American Economic Review, 98(4):1,692-706.

Hall, R. E. (2005). Employment fluctuations with equilibrium wage stickiness. American Economic Review, 95(1):50-65.

Klump, R., McAdam, P., and Willman, A. (2012). The normalized CES production function: theory and empirics. Journal of Economic Surveys, 26(5):769-799.

Krause, M. U., Lopez-Salido, D., and Lubik, T. A. (2008). Inflation dynamics with search frictions: A structural econometric analysis. Journal of Monetary Economics, 55(5):892-916.

Kurozumi, T. and Van Zandweghe, W. (2010). Labor market search, the Taylor principle, and indeterminacy. Journal of Monetary Economics, 57(7):851-858.

León-Ledesma, M. A., McAdam, P., and Willman, A. (2010a). Identifying the Elasticity of Substitution with Biased Technical Change. American Economic Review, 100(4):1330-57.

León-Ledesma, M. A., McAdam, P., and Willman, A. (2010b). In dubio pro CES - Supply estimation with mis-specified technical change. Working Paper Series, European Central Bank 1175, European Central Bank.

McAdam, P. and Willman, A. (2013). Technology, utilization, and inflation: What drives the new keynesian phillips curve? Journal of Money, Credit and Banking, 45(8):1547-1579.

Melina, G. and Villa, S. (2014). Fiscal policy and lending relationships. Economic Inquiry, $52(2): 696-712$.

Menzio, G. and Shi, S. (2011). Efficient search on the job and the business cycle. Journal of Political Economy, 119(3):468 - 510.

Monacelli, T., Quadrini, V., and Trigari, A. (2011). Financial markets and unemployment. NBER Working Papers 17389, National Bureau of Economic Research, Inc.

Mortensen, D. and Nagypal, E. (2007). More on unemployment and vacancy fluctuations. Review of Economic Dynamics, 10(3):327-347.

Pesavento, E. and Rossi, B. (2005). Do technology shocks drive hours up or down? A little evidence from an agnostic procedure. Macroeconomic Dynamics, 9(04):478-488.

Petrosky-Nadeau, N. (2013). Credit, vacancies and unemployment fluctuations. Review of Economic Dynamics, 17(2):191-205.

Pissarides, C. A. (2009). The unemployment volatility puzzle: is wage stickiness the answer? Econometrica, 77:1,339-369.

Quadrini, V. and Trigari, A. (2008). Public employment and the business cycle. Scandinavian Journal of Economics, 109(4):723-742.

Ravenna, F. and Walsh, C. E. (2008). Vacancies, unemployment, and the Phillips curve. European Economic Review, 52(8):1494-1521. 
Ravn, M. O., Schmitt-Grohe, S., and Uribe, M. (2006). Deep habits. Review of Economic Studies, 73(1):195-218.

Reiter, M. (2007). Embodied technical change and the fluctuations of unemployment and wages. The Scandinavian Journal of Economics, 109(4):695-721.

Robin, J.-M. (2011). On the dynamics of unemployment and wage distributions. Econometrica, 79(5):1327-1355.

Rotemberg, J. J. (2008). Cyclical wages in a search-and-bargaining model with large firms. In NBER International Seminar on Macroeconomics 2006, NBER Chapters, pages 65-114. National Bureau of Economic Research, Inc.

Shimer, R. (2005). The cyclical behavior of equilibrium unemployment and vacancies. American Economic Review, 95(1):25-49.

Smets, F. and Wouters, R. (2007). Shocks and frictions in US business cycles: A Bayesian DSGE approach. American Economic Review, 97(3):586-606.

Thomas, C. (2008). Search and matching frictions and optimal monetary policy. Journal of Monetary Economics, 55(5):936-956.

Zanetti, F. (2013). Financial shocks and labor market fluctuations. mimeo, University of Oxford. 


\begin{tabular}{cll}
\hline \hline Parameter & Description & Value \\
\hline$\beta$ & Discount factor & 0.99 \\
$\delta$ & Depreciation rate & 0.025 \\
$\epsilon$ & Elasticity of substitution & 6 \\
$\varphi$ & Inv. Frisch elasticity & 5 \\
$c / y$ & Consumption to GDP ratio & 0.67 \\
$g / y$ & Government Expenditure to GDP ratio & 0.19 \\
\hline \hline Target & Description & Value \\
\hline$u$ & Unemployment rate & 0.06 \\
$q(\theta)$ & Job filling rate & 0.70 \\
$\kappa_{v}$ & Vacancies to Output ratio & 0.01 \\
\hline
\end{tabular}

Table 1: Calibrated parameters/Targets

\begin{tabular}{|c|c|c|c|c|c|}
\hline \multirow[b]{2}{*}{ Parameters } & \multirow[b]{2}{*}{ Description } & \multicolumn{3}{|c|}{ Prior } & \multirow{2}{*}{$\begin{array}{l}\text { Posterior } \\
\text { Mean }\end{array}$} \\
\hline & & Distribution & Mean & $\mathrm{Std} / \mathrm{df}$ & \\
\hline \multicolumn{6}{|l|}{ Structural } \\
\hline$\zeta_{c}$ & Degree of Habits in $c$ & Beta & 0.5 & 0.15 & $0.86[0.79 ; 0.93]$ \\
\hline$\vartheta_{c}$ & Habit Persistence in $c$ & Beta & 0.5 & 0.15 & $0.86[0.78 ; 0.94]$ \\
\hline$\zeta_{g}$ & Degree of Habits in $g$ & Beta & 0.5 & 0.15 & $0.46[0.23 ; 0.71]$ \\
\hline$\vartheta_{g}$ & Habit Persistence in $g$ & Beta & 0.5 & 0.15 & $0.49[0.25 ; 0.73]$ \\
\hline$\sigma$ & Risk Aversion Coefficient & Normal & 2 & 0.2 & $2.08[1.76 ; 2.39]$ \\
\hline$\eta$ & Elasticity of K-L Substitution & Gamma & 1 & 1 & $0.18[0.13 ; 0.22]$ \\
\hline$\kappa_{p}$ & Price Stickiness & Gamma & 60.0 & 20.0 & $51.89[32.16 ; 73.34]$ \\
\hline$\omega_{p}$ & Price Indexation & Beta & 0.5 & 0.15 & $0.16[0.04 ; 0.27]$ \\
\hline$\kappa_{i}$ & Investment Adj. Cost & Gamma & 2 & 0.5 & $3.20[2.21 ; 4.16]$ \\
\hline$r_{\pi}$ & Taylor Rule Coeff. & Normal & 2.5 & 0.75 & $3.16[2.69 ; 3.61]$ \\
\hline$r_{r}$ & Interest Rate Smoothing & Beta & 0.50 & 0.15 & $0.85[0.82 ; 0.88]$ \\
\hline$r_{y}$ & Taylor Rule Coeff. & Normal & 0.5 & 0.15 & $0.45[0.27 ; 0.64]$ \\
\hline$\tilde{b}=\vec{b} / w h$ & Income Replacement Ratio & Beta & 0.40 & 0.15 & $0.61[0.51 ; 0.70]$ \\
\hline$\gamma$ & Elasticity of Matching & Beta & 0.5 & 0.10 & $0.25[0.20 ; 0.29]$ \\
\hline$\rho$ & Separation Rate & Beta & 0.1 & 0.02 & $0.14[0.11: 0.17]$ \\
\hline \multicolumn{6}{|l|}{ Shocks } \\
\hline$\varrho_{\ell}$ & Labor-augmenting shock & Beta & 0.5 & 0.15 & $0.91[0.88 ; 0.93]$ \\
\hline$\varsigma_{\ell}$ & & $\mathrm{IG}$ & 0.1 & 2 & $0.68[0.55 ; 0.81]$ \\
\hline$\varrho_{k}$ & Capital-augmenting shock & Beta & 0.5 & 0.15 & $0.92[0.88 ; 0.96]$ \\
\hline$\varsigma_{k}$ & & $\mathrm{IG}$ & 0.1 & 2 & $1.66[1.25 ; 2.05]$ \\
\hline$\varrho_{m}$ & Matching efficiency & Beta & 0.5 & 0.15 & $0.78[0.69 ; 0.87]$ \\
\hline$\varsigma_{m}$ & & $\mathrm{IG}$ & 0.1 & 2 & $1.18[0.89 ; 1.46]$ \\
\hline$\varrho_{c}$ & Preference shock & Beta & 0.5 & 0.15 & $0.89[0.84 ; 0.95]$ \\
\hline$\varsigma_{c}$ & & $\mathrm{IG}$ & 0.1 & 2 & $0.38[0.32 ; 0.43]$ \\
\hline$\varrho_{i}$ & Investment-specific shock & Beta & 0.5 & 0.15 & $0.66[0.57 ; 0.75]$ \\
\hline$\varsigma_{i}$ & & $\mathrm{IG}$ & 0.1 & 2 & $3.63[2.60 ; 4.58]$ \\
\hline$\varrho_{g}$ & Government spending shock & Beta & 0.5 & 0.15 & $0.98[0.97 ; 0.99]$ \\
\hline$\varsigma_{g}$ & & $\mathrm{IG}$ & 0.1 & 2 & $2.20[1.94: 2.47]$ \\
\hline$\varsigma_{r}$ & Monetary policy shock & IG & 0.1 & 2 & $0.14[0.12 ; 0.16]$ \\
\hline \multicolumn{6}{|l|}{ Rates } \\
\hline $\bar{\pi}$ & Inflation rate & Gamma & 0.625 & 0.10 & $0.78[0.70: 0.85]$ \\
\hline $\bar{v}_{n}$ & Unemployment and vacancies & Normal & 0.0 & 0.3 & $-0.40[-0.46:-0.34]$ \\
\hline$g_{r}$ & Trend & Normal & 0.4 & 0.1 & $0.46[0.43: 0.50]$ \\
\hline Log-likelihood & -887.31 & & & & \\
\hline
\end{tabular}

Table 2: Prior and posterior distributions 


\begin{tabular}{lccccc}
\hline & $\widehat{y}_{t}$ & $\widehat{i}_{t}$ & $\widehat{n}_{t}$ & $\widehat{u}_{t}$ & $\widehat{v}_{t}$ \\
\hline Relative standard deviations (to output) & & & & & \\
US data: 1984-2007 & 1 & 4.71 & 0.53 & 8.94 & 10.63 \\
Baseline Model (CES + DH + HM) & 1 & 3.22 & 0.53 & 8.25 & 9.18 \\
Model with CD, HM and DH & 1 & 5.24 & 0.28 & 4.35 & 4.92 \\
Model with CES and HM & 1 & 2.59 & 0.38 & 5.86 & 6.30 \\
Model without DH and HM & 1 & 2.74 & 0.28 & 4.34 & 3.92 \\
\hline Autocorrelations & & & & & \\
US data: 1984-2007 & 0.94 & 0.97 & 0.96 & 0.96 & 0.96 \\
Baseline Model (CES + DH + HM) & 0.98 & 0.97 & 0.98 & 0.98 & 0.95 \\
Model with CD , HM and DH & 0.98 & 0.99 & 0.92 & 0.92 & 0.78 \\
Model with CES and HM & 0.95 & 0.95 & 0.94 & 0.94 & 0.87 \\
Model without DH and HM & 0.95 & 0.94 & 0.92 & 0.92 & 0.85 \\
\hline Correlation with output & & & & & \\
US data: 1984-2007 & 1 & 0.92 & 0.56 & -0.59 & 0.69 \\
Model (CES PF + DH + HM) & 1 & 0.51 & 0.75 & -0.75 & 0.75 \\
Model with Cobb-Douglas PF, HM and DH & 1 & 0.54 & 0.80 & -0.80 & 0.79 \\
Model with CES PF and HM & 1 & 0.42 & 0.70 & -0.70 & 0.72 \\
Model without DH and HM & 1 & 0.39 & 0.57 & -0.57 & 0.66 \\
\hline
\end{tabular}

Table 3: Relative standard deviations in the data and the models. CD stands for Cobb-Douglas, DH for deep habits, and HM for Hagedorn and Manovskii. 


\begin{tabular}{|c|c|c|c|c|c|c|c|c|}
\hline & \multirow[t]{2}{*}{ Horizon } & \multicolumn{7}{|c|}{ Structural shocks } \\
\hline & & $\begin{array}{l}\text { Capital } \\
\text { aug., } \widehat{z}_{k t}\end{array}$ & $\begin{array}{l}\text { Labour } \\
\text { aug., } \widehat{z}_{\ell t}\end{array}$ & $\begin{array}{c}\text { Prefer., } \\
\widehat{z}_{c t}\end{array}$ & $\begin{array}{c}\text { Monet. } \\
\text { policy, } \epsilon_{r t}\end{array}$ & $\begin{array}{c}\text { Fiscal, } \\
\widehat{g}_{t}\end{array}$ & $\begin{array}{l}\text { Invest. } \\
\text { spec., } \widehat{z}_{i t}\end{array}$ & $\begin{array}{l}\text { Match. } \\
\text { effic., } \widehat{\bar{m}}_{t}\end{array}$ \\
\hline \multirow[t]{6}{*}{ Output, $\hat{y}_{t}$} & 1 & 8.31 & 3.11 & 36.62 & 1.69 & 34.27 & 15.91 & 0.09 \\
\hline & 4 & 19.27 & 13.02 & 30.29 & 1.20 & 19.25 & 16.68 & 0.30 \\
\hline & 8 & 28.89 & 19.74 & 25.66 & 0.78 & 12.47 & 12.02 & 0.43 \\
\hline & 20 & 35.77 & 26.80 & 19.48 & 0.47 & 7.47 & 9.60 & 0.40 \\
\hline & 40 & 35.90 & 31.26 & 15.48 & 0.39 & 6.16 & 10.43 & 0.38 \\
\hline & uncond. & 34.50 & 32.40 & 15.22 & 0.37 & 6.59 & 10.55 & 0.36 \\
\hline \multirow[t]{6}{*}{ Mark-ups, $\hat{\mu}_{t}$} & 1 & 38.53 & 23.22 & 4.50 & 6.13 & 2.29 & 24.15 & 1.18 \\
\hline & 4 & 31.33 & 16.00 & 8.04 & 7.12 & 1.65 & 34.51 & 1.36 \\
\hline & 8 & 30.72 & 15.91 & 8.97 & 6.80 & 3.31 & 33.03 & 1.26 \\
\hline & 20 & 31.71 & 17.06 & 8.27 & 5.71 & 6.97 & 29.16 & 1.13 \\
\hline & 40 & 29.68 & 17.41 & 10.98 & 5.20 & 8.36 & 27.34 & 1.04 \\
\hline & uncond. & 29.14 & 17.28 & 12.36 & 5.02 & 8.63 & 26.57 & 1.01 \\
\hline \multirow[t]{6}{*}{ Wage, $\hat{w}_{t}$} & 1 & 6.09 & 34.43 & 5.28 & 9.56 & 1.63 & 38.41 & 4.60 \\
\hline & 4 & 37.32 & 12.29 & 4.59 & 5.74 & 1.12 & 35.95 & 3.00 \\
\hline & 8 & 55.47 & 8.45 & 2.83 & 3.26 & 2.76 & 25.68 & 1.55 \\
\hline & 20 & 56.15 & 12.14 & 2.05 & 1.70 & 6.25 & 20.82 & 0.89 \\
\hline & 40 & 48.13 & 16.89 & 4.76 & 1.26 & 9.20 & 19.04 & 0.72 \\
\hline & uncond. & 44.94 & 17.41 & 7.73 & 1.16 & 10.07 & 18.02 & 0.67 \\
\hline \multirow[t]{6}{*}{ Unempl., $\hat{u}_{t}$} & 1 & 6.21 & 23.30 & 4.11 & 7.63 & 0.97 & 30.55 & 27.23 \\
\hline & 4 & 33.61 & 7.06 & 3.77 & 4.76 & 0.69 & 29.62 & 20.50 \\
\hline & 8 & 52.16 & 5.30 & 2.34 & 2.69 & 2.40 & 21.66 & 13.45 \\
\hline & 20 & 54.62 & 10.29 & 1.76 & 1.40 & 6.01 & 18.62 & 7.31 \\
\hline & 40 & 47.09 & 15.51 & 4.49 & 1.04 & 9.03 & 17.47 & 5.38 \\
\hline & uncond. & 43.96 & 16.16 & 7.48 & 0.96 & 9.93 & 16.57 & 4.95 \\
\hline \multirow[t]{6}{*}{ Vacancies, $\hat{v}_{t}$} & 1 & 8.39 & 31.46 & 5.56 & 10.30 & 1.31 & 41.26 & 1.72 \\
\hline & 4 & 39.54 & 12.19 & 4.30 & 5.78 & 1.35 & 33.65 & 3.17 \\
\hline & 8 & 55.49 & 9.17 & 2.68 & 3.43 & 2.99 & 24.40 & 1.84 \\
\hline & 20 & 55.48 & 12.61 & 2.12 & 1.87 & 6.35 & 20.52 & 1.05 \\
\hline & 40 & 47.81 & 17.06 & 4.81 & 1.41 & 9.21 & 18.86 & 0.84 \\
\hline & uncond. & 44.79 & 17.52 & 7.68 & 1.30 & 10.04 & 17.89 & 0.78 \\
\hline
\end{tabular}

Table 4: Variance decomposition 

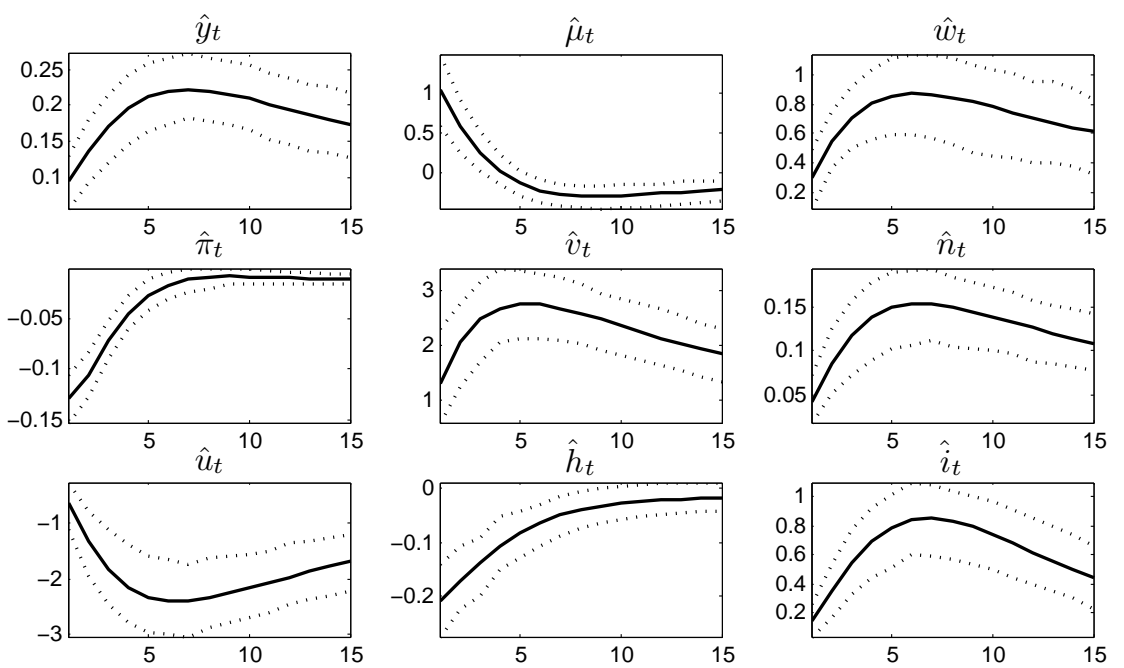

Figure 1: Capital-augmenting technology shock. Solid lines represent mean IRF and dashed lines represent the $95 \%$ confidence intervals.
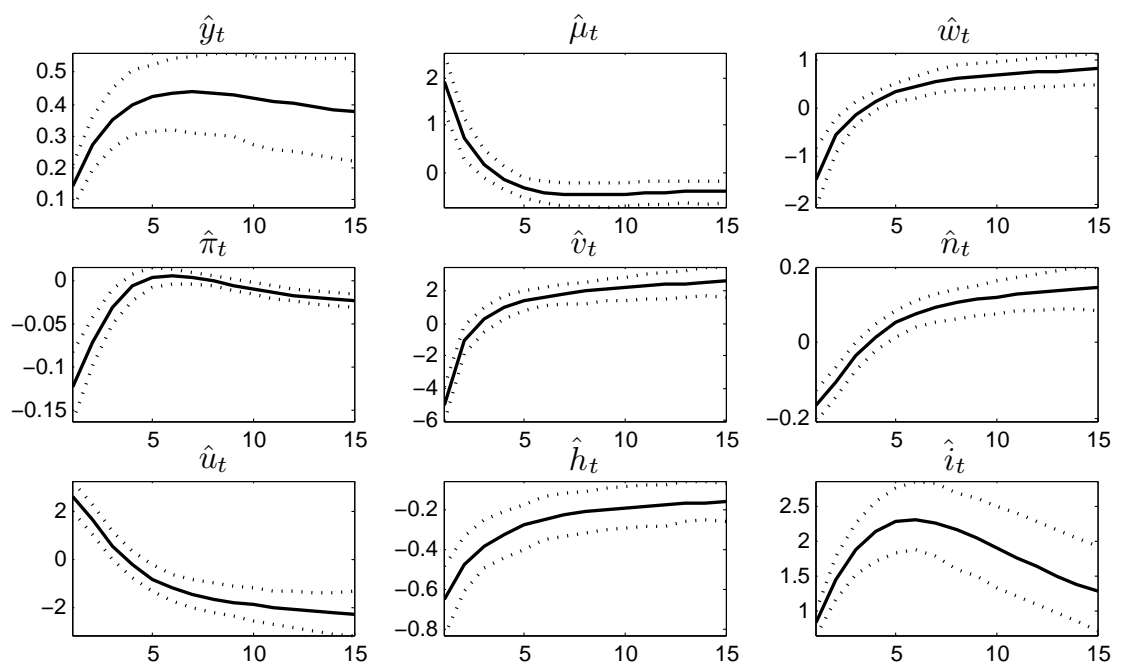

Figure 2: Labour-augmenting technology shock. Solid lines represent mean IRF and dashed lines represent the $95 \%$ confidence intervals.
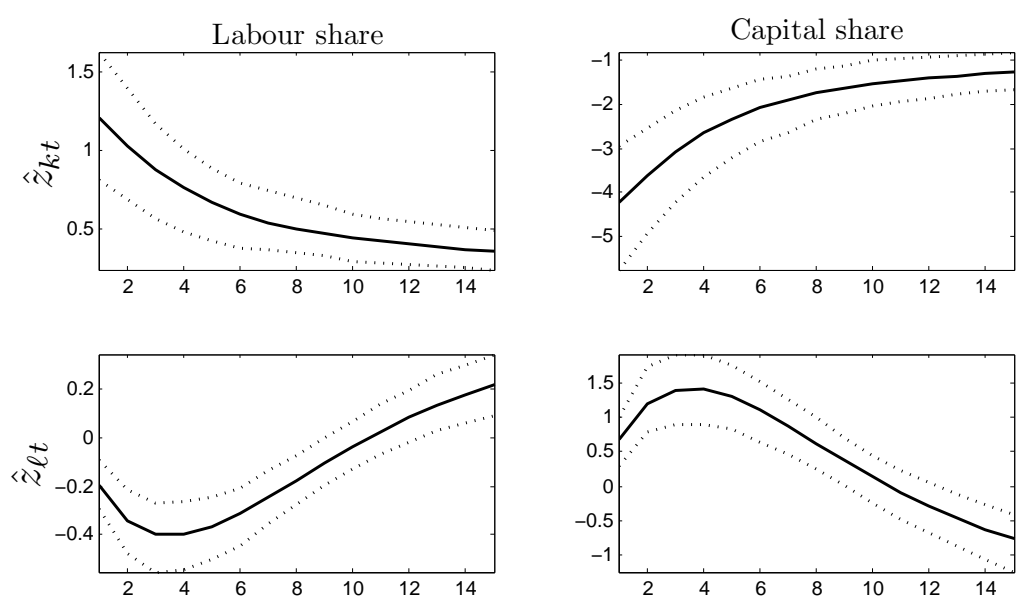

Figure 3: Labour and capital income shares in response to capital and labour-augmenting technology shocks. Solid lines represent mean IRF and dashed lines represent the $95 \%$ confidence intervals. 

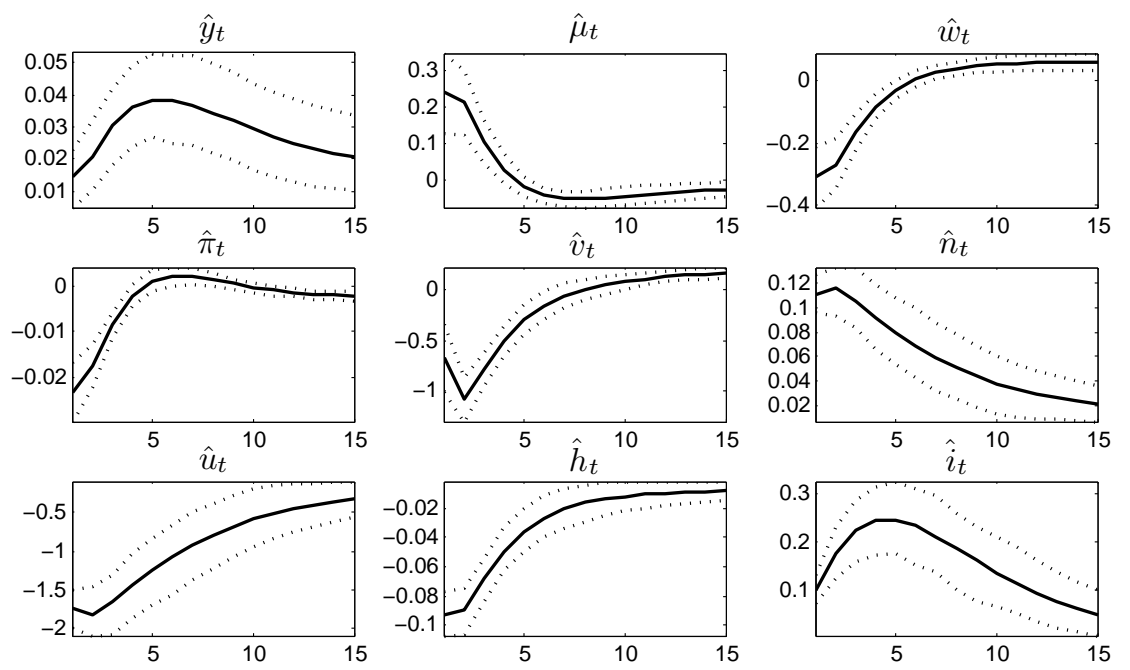

Figure 4: Matching efficiency shock. Solid lines represent mean IRF and dashed lines represent the $95 \%$ confidence intervals.
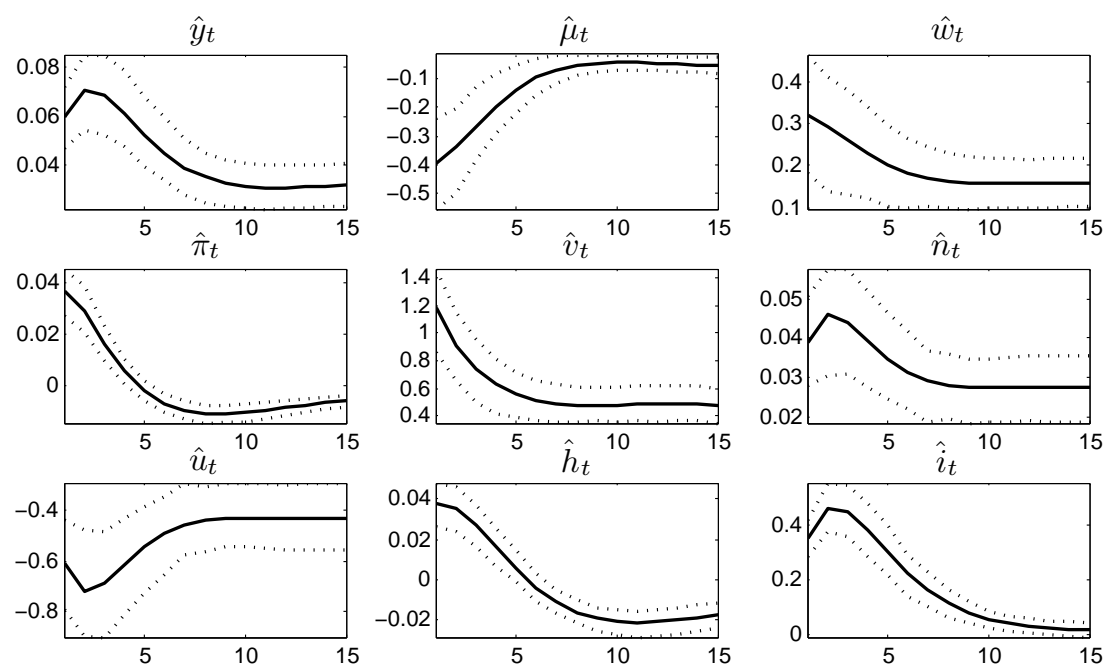

Figure 5: Investment-specific shock. Solid lines represent mean IRF and dashed lines represent the $95 \%$ confidence intervals.
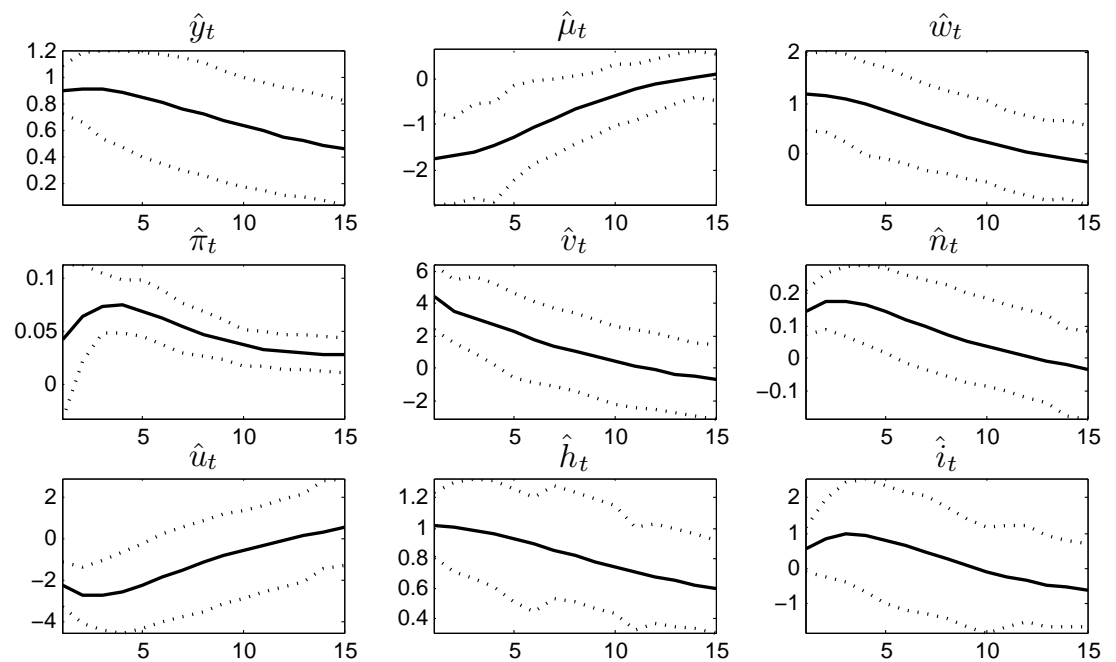

Figure 6: Preference shock. Solid lines represent mean IRF and dashed lines represent the $95 \%$ confidence intervals. 

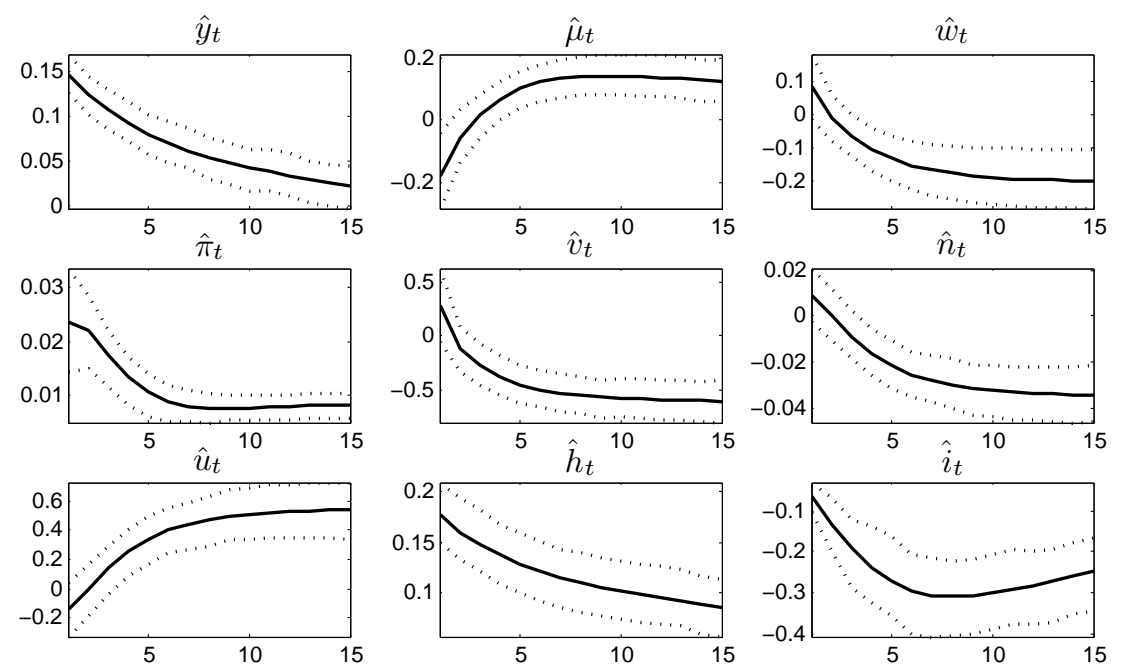

Figure 7: Government spending shock. Solid lines represent mean IRF and dashed lines represent the $95 \%$ confidence intervals.
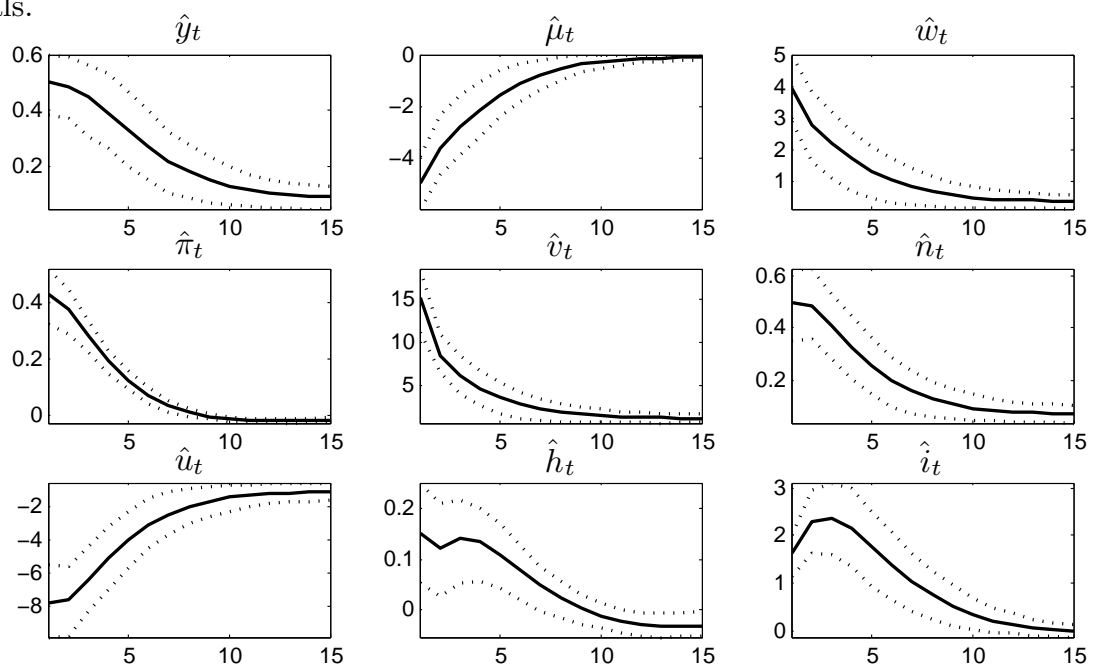

Figure 8: Monetary policy shock. Solid lines represent mean IRF and dashed lines represent the $95 \%$ confidence intervals. 

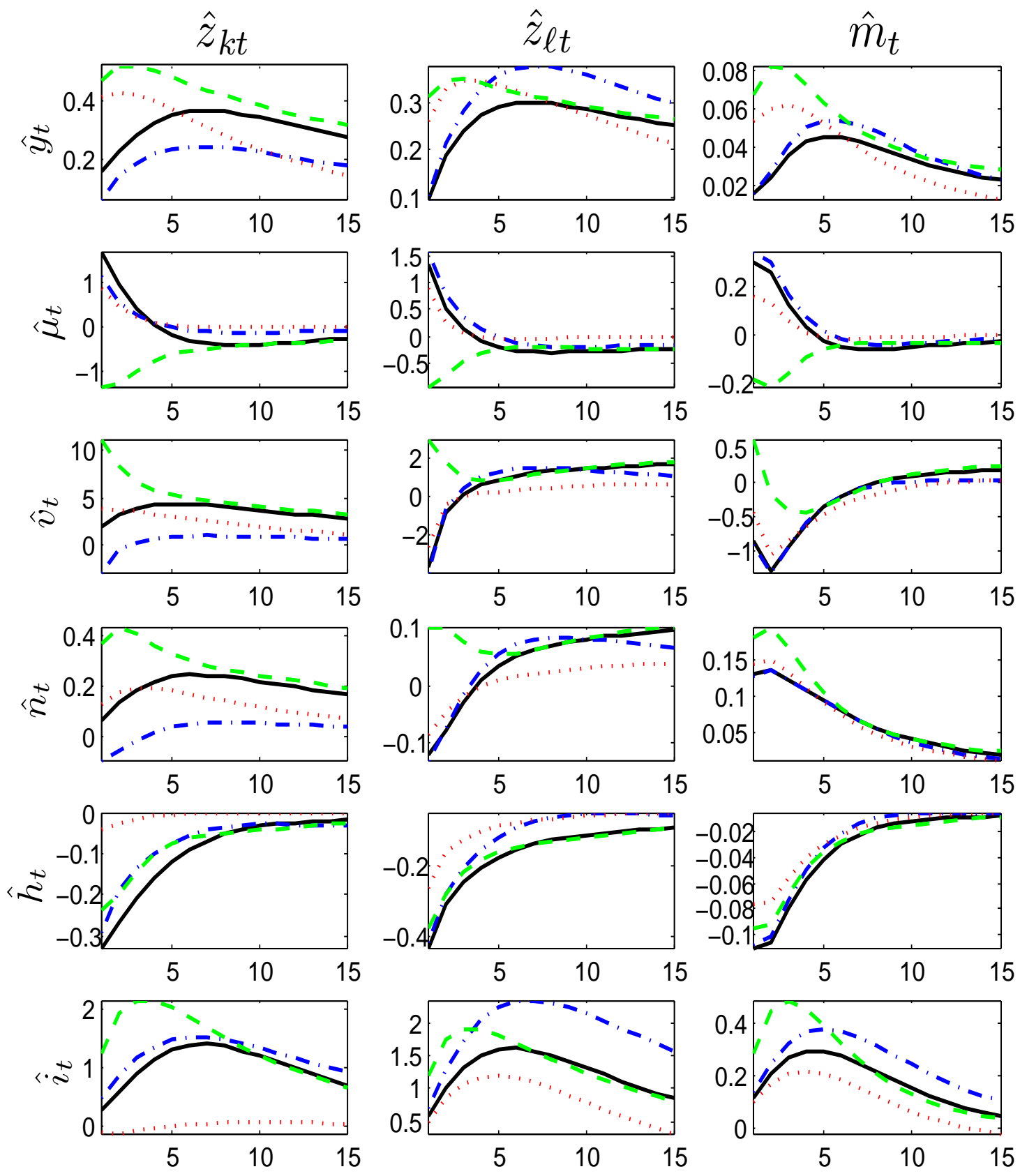

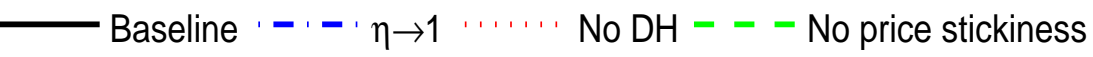

Figure 9: Counter-factual exercises. Impulse responses to a capital-augmenting technology shock, a labouraugmenting technology shock and a matching efficiency shock in 4 models: baseline, Cobb-Douglas production function $(\eta \rightarrow 1)$, no deep habits $(\mathrm{DH})$, no price stickiness. Each feature of the model is removed one at a time. 

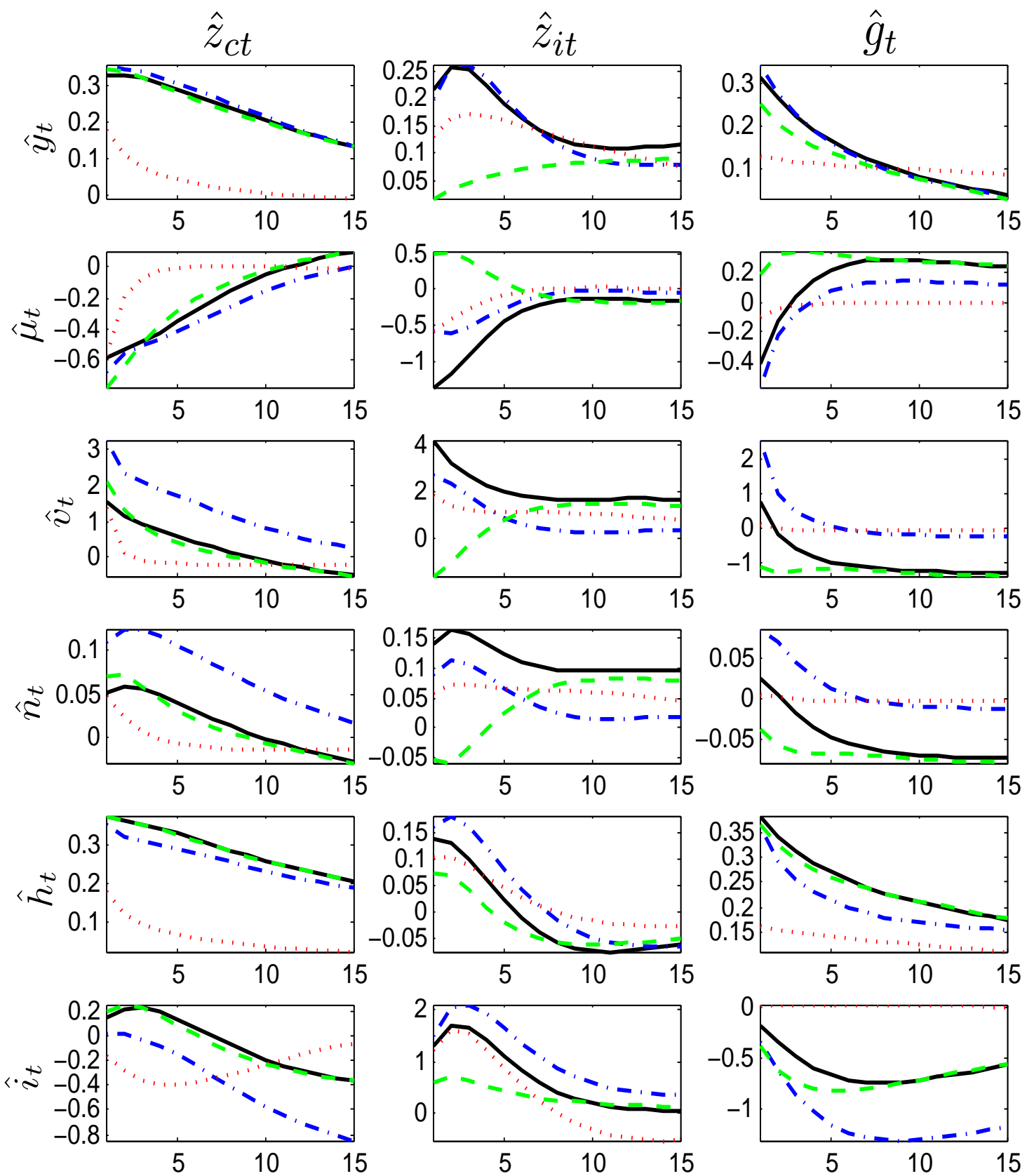

\section{- Baseline ' - - $\eta \rightarrow 1 \cdots \cdots$, No $\mathrm{DH}=-$ No price stickiness}

Figure 10: Counter-factual exercises. Impulse responses to preference, investment-specific technology and government shocks in 4 models: baseline, Cobb-Douglas production function $(\eta \rightarrow 1)$, no deep habits $(\mathrm{DH})$, no price stickiness. Each feature of the model is removed one at a time. 


\section{Appendix}

\section{A Data Transformation and Estimation Procedure}

Data on real personal consumption expenditure (PCE), investment, GDP and the implicit price deflator of GDP are drawn from the Bureau of Economic Analysis. Data on civilian noninstitutional labour force (LNS11000000Q) and the unemployment rate (LNS14000000Q) are taken from the Bureau of Labor Statistics. The fed funds rate is downloaded from the FRED(c) database of the Federal Reserve Bank of St. Louis. We build a composite measure of the Help-Wanted Index (HWI) following Barnichon (2010).

Data are transformed following Smets and Wouters (2007) with some minor adjustments. Consumption is expressed in per worker terms rather than in per capita terms and then logged. Nominal variables are deflated using the implicit price deflator of GDP. The inflation rate is computed as a quarter on quarter difference of the log of the implicit GDP deflator. The federal funds rate is expressed in quarterly terms. We take the log of the unemployment rate and the $\log$ of vacancies. The series on vacancies is computed as a vacancy rate, denoted as the ratio between total vacancies and the civilian labor force (LNS11000000Q). The vacancy rate is computed as the product of the composite HWI index and the number of unemployed workers (LNS13000000Q) in 1987, which is the base year of the HWI.

We add the following measurement equations to establish a link between the observable variables and their corresponding endogenous variables in our model

$$
\left[\begin{array}{c}
d c_{t} \\
d i_{t} \\
d y_{t} \\
i n f l_{t} \\
f f r_{t} \\
d u_{t} \\
d v_{t}
\end{array}\right]=\left[\begin{array}{c}
\bar{g}_{r} \\
\bar{g}_{r} \\
\bar{g}_{r} \\
\bar{\pi} \\
\bar{r} \\
\bar{u}_{n} \\
\bar{u}_{n}
\end{array}\right]+\left[\begin{array}{c}
\widehat{c}_{t}-\widehat{c}_{t-1} \\
\widehat{i}_{t}-\widehat{i}_{t-1} \\
\widehat{y}_{t}-\widehat{y}_{t-1} \\
\widehat{\pi}_{t} \\
\widehat{r}_{t} \\
\widehat{u}_{t}-\widehat{u}_{t-1} \\
\widehat{v}_{t}-\widehat{v}_{t-1}
\end{array}\right]
$$

where $\bar{g}_{r}$ represents the trend growth rate of consumption, investment and output; $\bar{\pi}$ is the net steady state inflation rate, which is different from the gross inflation rate, $\pi$; here, the bar over the variables, $\bar{r}$ and $\bar{u}_{n}$ indicate the sample mean. The number of variables in the data coincides with the number of shocks in the model.

To solve the model, we take a first-order (log) approximation of the system of equations around the deterministic steady state. We use standard methods to solve linear rational expectation models and then we apply the Kalman filter to evaluate the likelihood function of the observable variables. The likelihood function and the prior distribution of the parameters are combined to calculate the posterior distributions. The posterior Kernel is then simulated numerically using the Metropolis-Hasting algorithm. The posterior distribution of all estimated parameters is obtained in two steps. First, we use the csminwel algorithm by Christopher Sims to explore the posterior mode and to approximate the variance-covariance matrix, based on the inverse Hessian matrix evaluated at the mode, by numerical optimisation on the log posterior density. Second, the posterior is explored using the random walk Metropolis Hastings algorithm with two chains of 250,000 draws each. This Markov Chain Monte Carlo (MCMC) method generates draws from the posterior density and updates the candidate parameters after each draw. Version 4.3.3 of the Dynare toolbox for Matlab is used for the computations. 
$\zeta_{c}$
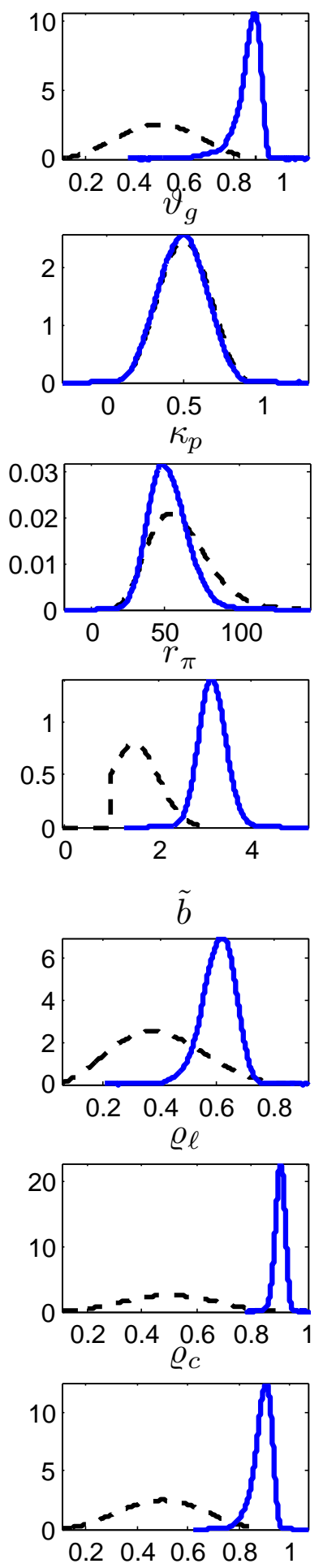
$g_{r}$

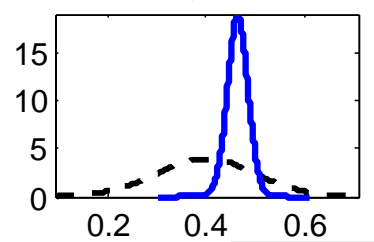

$\begin{array}{lll}0.2 & 0.4 & 0.6\end{array}$
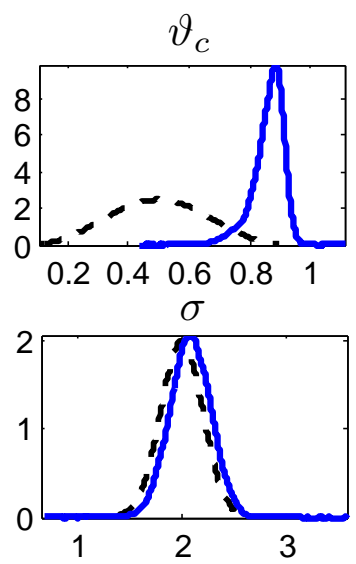

$\omega_{p}$
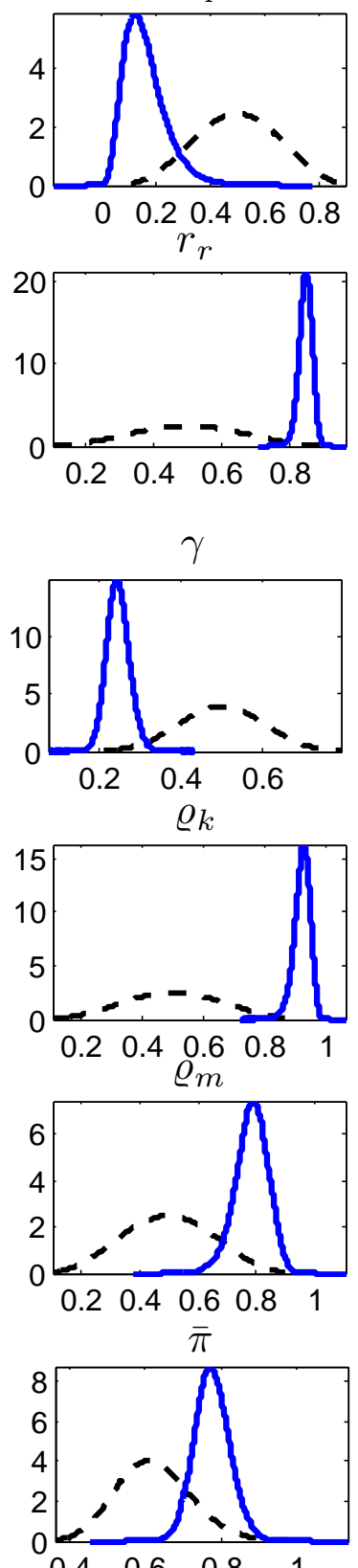

Posterior density
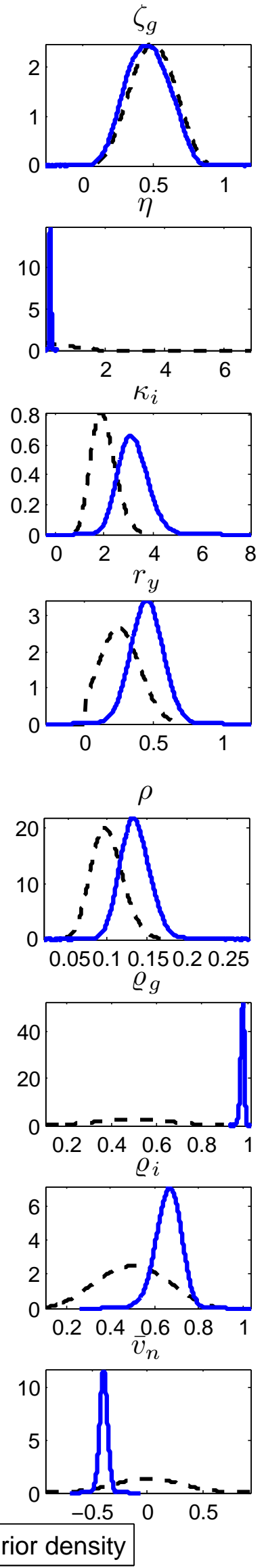

Figure A.1: Prior and posterior probability densities of the estimated parameters 

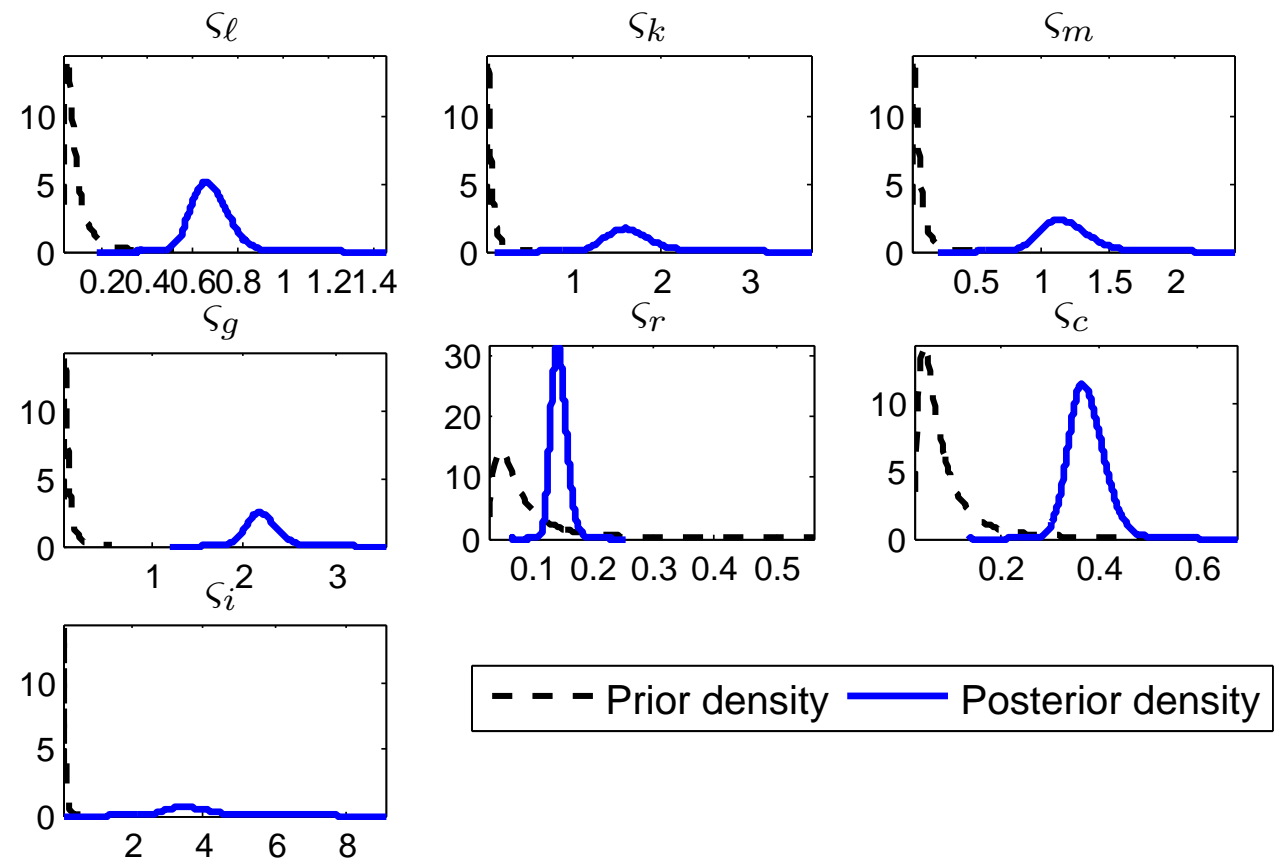

Figure A.2: Prior and posterior probability densities of the estimated parameters

\section{B The Model}

\section{B.1 The Household's Problem}

The economy is populated by a unit measure of identical households, indexed by $j \in[0,1]$. Workers within each households can be employed or unemployed. The employed members of the household at firm $f$ receive a nominal hourly wage rate $W_{f t}^{j}$. Working is costly in utility terms. Each member of the household works $h_{f t}^{j}$ amount of hours. The unemployed members receive unemployment benefits for the amount $\bar{b}$. In accordance with Andolfatto (1996), we assume that workers can perfectly insure against idiosyncratic shocks within the household. Households consume a variety of final goods indexed by $i \in[0,1]$ and, following Ravn et al. (2006), we assume that the household's utility exhibits external habit formation in consumption at the good-specific level rather than at the aggregate level. This type of consumption externality has been coined as external deep habits or, alternatively, as catching-up with the Joneses good by good.

Household $j$ faces two decision problems: an intra-temporal and an inter-temporal problem. The former is to minimise total consumption expenditure, $\int_{0}^{1} P_{f t} c_{f t}^{j} d f$, subject to the following consumption object

$$
\left(x_{t}^{c}\right)^{j}=\left[\int_{0}^{1}\left(c_{f t}^{j}-\zeta_{c} s_{f t-1}^{c}\right)^{1-1 / \epsilon} d f\right]^{1 /(1-1 / \epsilon)},
$$

where $s_{f t}^{c}$ denotes the stock of external habit in private consumption of variety $f$ at time $t$, $\zeta_{c} \in[0,1)$ the degree of external habit formation of each variety and $\epsilon$ the intra-temporal elasticity of substitution of habit adjusted consumption across varieties. The aggregate stock of habits for variety $f$ evolves over time according to

$$
s_{f t}^{c}=\vartheta_{c} s_{f t-1}^{c}+\left(1-\vartheta_{c}\right) c_{f t},
$$

where the parameter $\vartheta_{c} \in[0,1)$ measures the speed of adjustment of the habit stock to changes in the average level of consumption of variety $f$. A value of $\vartheta_{c}$ equal to 0 implies that the habit stock displays no persistence. By minimising expenditure with respect to $c_{f t}^{j}$, we can derive the 
individual consumption demands of variety $f$ by household $j$

$$
c_{f t}^{j}=\left(\frac{P_{f t}}{P_{t}}\right)^{-\epsilon}\left(x_{t}^{c}\right)^{j}+\zeta_{c} s_{f t-1}^{c},
$$

where $P_{t} \equiv\left[\int_{0}^{1} P_{f t}^{1-\epsilon} d i\right]^{\frac{1}{1-\epsilon}}$ is the nominal price index and $P_{f t}$ is the price of good $f$. The consumption demand for each variety $f$ is decreasing in the relative price of good $f, P_{f t} / P_{t}$, and increasing in both the level of habit adjusted consumption, $\left(x_{t}^{c}\right)^{j}$, and, for positive values of $\zeta_{c}$, in the external level of consumption habits, $s_{f t-1}^{c}$. Nominal expenditure in habit adjusted consumption can be also expressed as $P_{t}\left(x_{t}^{c}\right)^{j}=\int_{0}^{1} P_{f t}\left(c_{f t}^{j}-\zeta_{c} s_{f t-1}^{c}\right) d i$.

The second problem of household $j$ is to maximise her lifetime utility by choosing the consumption object, $\left(x_{t}^{c}\right)^{j}$, nominal bond holdings, $B_{t}^{j}$, physical capital, $k_{t}^{j}$, and investment, $i_{t}^{j}$. The period utility depends positively on habit-adjusted consumption and negatively on labour supply; it is defined by

$$
\mathcal{U}\left[\left(x_{t}^{c}\right)^{j}, h_{f t}^{j}, n_{f t}^{j}\right]=\frac{\left[\left(x_{t}^{c}\right)^{j}-\ln \left(z_{c t}\right)\right]^{1-\sigma}-1}{1-\sigma}-\chi \int_{0}^{1} n_{f t}^{j} \frac{\left(h_{f t}^{j}\right)^{1+\varphi}}{1+\varphi} d f,
$$

where $\chi$ is a constant, $\sigma$ denotes the inverse of the inter-temporal elasticity of substitution between the consumption object at time $t$ and $t+1$ and $\varphi$ the inverse of the Frisch elasticity of labour supply. The term $n_{f t}^{j}$ denotes the employment rate by household $j$. The variable $z_{c t}$ is a preference shock that evolves according to the following law of motion

$$
\ln z_{c t}=\varrho_{c} \ln z_{c t-1}+\varepsilon_{c t} \quad \text { with } \quad \varepsilon_{c t} \sim N\left(0, \varsigma_{c}\right),
$$

where $\varrho_{c}$ is the persistence of the preference shock and $\varsigma_{c}$ is the standard deviation of the innovation $\varepsilon_{c t}$. As the preference shock enters with a negative sign in the utility function, an expansionary preference shock requires higher levels of habit adjusted consumption to maintain the same level of utility as in Ravn et al. (2006). ${ }^{10}$ The life-time utility of household $j$ is given by

$$
\mathcal{V}_{t}=E_{t} \sum_{\tau=t}^{\infty} \beta^{\tau-t} \mathcal{U}\left(\left(x_{\tau}^{c}\right)^{j}, n_{f \tau}^{j}, h_{f \tau}^{j}\right)
$$

where $E_{t}$ is the mathematical expectation operator conditional on the information available at time $t$ and $\beta \in(0,1)$ is the subjective discount factor. The nominal budget constraint of household $j$ is given by

$$
P_{t}\left(x_{t}^{c}\right)^{j}+P_{t} \tilde{x}_{t}^{c}+P_{t} i_{t}^{j}+B_{t}^{j}=R_{t-1} B_{t-1}^{j}+\int_{0}^{1} W_{f t}^{j} n_{f t}^{j} h_{f t}^{j} d f+\left(1-n_{t}^{j}\right) P_{t} \bar{b}+P_{t} r_{k t} k_{t-1}^{j}+\Phi_{t}^{j}+P_{t} \bar{\tau}_{t}^{j},
$$

where $\tilde{x}_{t}^{c}$ is equal to $\zeta_{c} \int_{0}^{1} \frac{P_{f t}}{P_{t}} s_{f t-1}^{c} d i, i_{t}^{j}$ investment in physical capital by the household, the term $\left(1-n_{t}^{j}\right) P_{t} \bar{b}$ are the benefits received by the unemployed members of household $j, k_{t-1}^{j}$ the amount of physical capital, $r_{k t}$ the real rental rate of capital, $\Phi_{t}^{j}$ are the aggregate nominal profits distributed to each household $j$ at time $t$ and $\bar{\tau}_{t}^{j}$ the lump-sum taxes paid by the household to the government at time $t$. We denote by $R_{t}$ the nominal interest rate paid for holding nominal bonds. Households face an additional constraint (not shown for brevity) that prevents households from running Ponzi schemes. At the household level $j$, the law of motion of employment evolves according to

$$
n_{t}^{j}=(1-\rho) n_{t-1}^{j}+\theta_{t} q\left(\theta_{t}\right) u_{t}^{j}
$$

\footnotetext{
${ }^{10}$ Modelling the preference shock additively is innocuous for our results.
} 
and the law of motion of physical capital is

$$
\left[1-\frac{\kappa_{i}}{2}\left(\frac{i_{t}^{j}}{i_{t-1}^{j}}-1\right)^{2}\right] z_{i t} i_{t}^{j}=k_{t}^{j}-(1-\delta) k_{t-1}^{j},
$$

where $\kappa_{i}$ is an adjustment cost associated with changes in investment, $\delta$ the depreciation rate, $z_{i t}$ an investment-specific shock that obeys the following exogenous process

$$
\ln \left(z_{i t}\right)=\varrho_{i} \ln \left(z_{i t-1}\right)+\varepsilon_{f t} \quad \text { with } \quad \varepsilon_{f t} \sim N\left(0, \varsigma_{i}\right) .
$$

Household $j$ maximises (40) by choosing the processes $\left(x_{t}^{c}\right)^{j}, B_{t}^{j}, k_{t}^{j}$ and $i_{t}^{j}$ subject to conditions (41) and (43). The household takes $\Phi_{t}^{j}, \tilde{x}_{t}^{c}, s_{f t-1}^{c}, i_{t-1}^{j}, k_{t-1}^{j}, P_{t}, B_{t-1}^{j}$ and $\bar{\tau}_{t}^{j}$ as given. The first order conditions of this problem are

$$
\begin{gathered}
\lambda_{t}^{j}=\left[\left(x_{t}^{c}\right)^{j}-\ln \left(z_{c t}\right)\right]^{-\sigma}, \\
\lambda_{t}^{j}=\beta R_{t} E_{t} \frac{\lambda_{t+1}^{j}}{\pi_{t+1}}, \\
\lambda_{t}^{j} q_{k t}=\lambda_{t+1}^{j} \beta E_{t}\left[r_{k t+1}+(1-\delta) q_{k t+1}\right]
\end{gathered}
$$

and

$$
\begin{aligned}
\lambda_{t}^{j}= & q_{k t} \lambda_{t}^{j} z_{i t}\left\{\left[1-\frac{\kappa_{i}}{2}\left(\frac{i_{t}^{j}}{i_{t-1}^{j}}-1\right)^{2}\right]-\kappa_{i} \frac{i_{t}^{j}}{i_{t-1}^{j}}\left(\frac{i_{t}^{j}}{i_{t-1}^{j}}-1\right)\right\}+ \\
& +\beta \kappa_{i} E_{t} q_{k t+1} \lambda_{t+1}^{j} z_{i t+1}\left(\frac{i_{t+1}^{j}}{i_{t}^{j}}\right)^{2}\left(\frac{i_{t+1}^{j}}{i_{t}^{j}}-1\right),
\end{aligned}
$$

where $\pi_{t}$ denotes the gross inflation rate at time $t$, defined as $P_{t} / P_{t-1}, \lambda_{t}^{j}$ and $\lambda_{t}^{j} q_{k t}$ are the Lagrange multipliers associated with constraints (41) and (43). Equation (45) is the marginal utility of habit adjusted consumption, equation (46) the standard Euler condition with respect to bond holdings and equation (47) the corresponding Euler equation with respect to physical capital. By non-arbitrage, the two Euler equations set the marginal cost of habit adjusted consumption at time $t$ equal to the marginal benefit at time $t+1$ expressed in terms of time $t$. Finally, equation (48) describes the relationship between investment dynamics and the relative price of capital, also known as Tobin's q.

In addition, the non-arbitrage condition with respect to employment is given by

$$
\mathcal{W}_{f t}^{j}=\frac{W_{f t}^{j}}{P_{t}} h_{f t}^{j}-\left[\bar{b}+\frac{\chi\left(h_{f t}^{j}\right)^{1+\varphi}}{(1+\varphi) \lambda_{t}^{i}}\right]+E_{t} \beta \frac{\lambda_{t+1}^{j}}{\lambda_{t}^{j}}(1-\rho) \mathcal{W}_{f t+1}^{j}\left[1-\theta_{t+1} q\left(\theta_{t+1}\right)\right]
$$

where $\mathcal{W}_{f t}^{j}$ denotes the net value to the household of having an additional worker employed at firm $f$. The net value of employment to household $j$ is equal to the flow value of employment wage income minus the opportunity cost of being employed at firm $f$ - plus the net continuation value of employment at the firm minus the net value of finding an equivalent job elsewhere whilst searching for a job at time $t$. Hence, the aggregate labour market conditions influence the value of employment to the household $j$ at firm $f$ through fluctuations in the job finding rate, $\theta_{t} q\left(\theta_{t}\right)$. 


\section{B.2 The Firm's Problem}

There is a unit mass of monopolistically competitively firms, each of which produces a particular variety of the final good, indexed by $f \in[0,1]$. The assumption of monopolistic competition entails that each firm sets their own price by taking the aggregate price level as given. At the announced price, each firm stands ready to meet the demand for its own variety. Firms face nominal price adjustment costs. Each variety $f$ is produced using two inputs: labour, $\ell_{f t}=n_{f t} h_{f t}$, and capital $k_{f t-1}$. While the labour input can vary along the intensive margin, $h_{f t}$, and the extensive margin, $n_{f t}$, physical capital can only vary along the extensive margin. ${ }^{11}$ The factors of production are subject to different adjustment lags: i) hired workers become immediately productive and ii) physical capital only adjusts with a lag. Furthermore, factor adjustments are costly due to the presence search and matching frictions and investment adjustment costs. Following León-Ledesma et al. (2010a), the production function is of the Constant Elasticity of Substitution form

$$
y_{f t}=\left[\alpha_{k}\left(z_{k t} k_{f t-1}\right)^{\frac{\eta-1}{\eta}}+\alpha_{\ell}\left(z_{\ell t} \ell_{f t}\right)^{\frac{\eta-1}{\eta}}\right]^{\frac{\eta}{\eta-1}}=c_{f t}+g_{f t}+i_{f t}
$$

where variable $y_{f t}$ denotes the output of firm $f, z_{k t}$ a capital-augmenting technology shock, $z_{\ell t}$ a labour-augmenting technology shock and $\alpha_{k}$ and $\alpha_{\ell}$ the distribution parameters. In accordance with Cantore and Levine (2012), the distribution parameters do not represent factor income shares and have dimensions that depend on the measurement units of capital and labour. Therefore, the distribution parameters are meaningless and can be obtained indirectly by calibrating the steady state labour and capital shares. The parameter $\eta$ measures the elasticity of substitution between labour and capital. The CES production function, (50), nests the CobbDouglas production function when $\eta=1$; the Leontief function (i.e., fixed factor proportions) when $\eta=0$; and a linear production function (i.e., perfect factor substitutes) when $\eta \rightarrow \infty$. When $\eta<1$, we say that factors are gross complements in production; factors are gross substitutes otherwise. This CES technology exhibits diminishing marginal returns, which in turn generates downward sloping factor demand curves. Firm f's output is equal to the sum of three component of expenditure: investment in physical capital, private consumption and government expenditure. Finally, the exogenous technological processes $z_{\ell t}$ and $z_{k t}$ evolve according to

$$
\ln \left(z_{x t} / z_{x}\right)=\varrho_{x} \ln \left(z_{x t-1} / z_{x}\right)+\varepsilon_{x t} \quad \text { with } \quad \varepsilon_{x t} \sim N\left(0, \varsigma_{x}\right) \quad \text { for } \quad x=\{\ell, k\},
$$

where $\varrho_{x}$ denotes the persistence of the productivity innovations and $\varsigma_{x}$ the standard deviation of the innovations $\varepsilon_{x t}$.

Each firm $f$ faces a consumption demand schedule that result from the inter-temporal maximisation problem of households and the government (which has been omitted for expositional purposes). By adding up the cross-sectional individual demands, we can recover the demand for good $f$. Analytically, we simply integrate expression (37) over $j$ to obtain

$$
c_{f t}=\left(\frac{P_{f t}}{P_{t}}\right)^{-\epsilon} x_{t}^{c}+\zeta_{c} s_{f t-1}^{c},
$$

and, equivalently, we can obtain the individual demands by the government

$$
g_{f t}=\left(\frac{P_{f t}}{P_{t}}\right)^{-\epsilon} x_{t}^{g}+\zeta_{c} s_{f t-1}^{g}
$$

where

$$
s_{f t}^{g}=\vartheta_{g} s_{f t-1}^{g}+\left(1-\vartheta_{g}\right) g_{f t},
$$

\footnotetext{
${ }^{11}$ We have experimented with the introduction of an intensive margin in the capital input and found that our results do not change.
} 
$x_{t}^{c}=\int_{0}^{1} x_{f t}^{c} d i$ is a habit adjusted measure of aggregate private consumption and $x_{t}^{g}$ the corresponding measure of aggregate public consumption. The individual demand of good $f$ depends on a price elastic term, $\left(P_{f t} / P_{t}\right)^{-\epsilon} x_{c t}$, and a price inelastic term $\zeta_{c} s_{f t-1}^{c}$. Higher aggregate demand increases the weight of the price elastic term. Since mark-ups are inversely related to the price elasticity of demand, the deep habits mechanism predicts that demand/supply shocks generate counter-cyclical/pro-cyclical movements in mark-ups.

Unlike consumption demands, individual investment demands are not subject to deep habits and is given by

$$
i_{f t}=\left(\frac{P_{f t}}{P_{t}}\right)^{-\epsilon} i_{t}
$$

Real profits, $\phi_{f t}$, of firm $f$ at time $t$ can be written as

$$
\frac{\Phi_{f t}}{P_{t}}=\phi_{f t}=\frac{P_{f t}}{P_{t}}\left(c_{f t}+g_{f t}+i_{f t}\right)-\frac{W_{f t} \ell_{f t}}{P_{t}}-r_{k t} k_{f t-1}-\kappa_{v} v_{f t}-\mathcal{A}_{f t},
$$

where $\mathcal{A}_{f t}$ defines the price adjustment costs expressed in terms of output, $\frac{\kappa_{p}}{2}\left(\frac{P_{f t}}{P_{f t-1} \tilde{\pi}_{t}^{p}}-1\right)^{2} y_{t}$, $\tilde{\pi}_{t}=\pi_{t-1}^{\omega_{p}} \pi^{1-\omega_{p}}$ and $\omega_{p}$ is the degree of price indexation. As standard in the search and matching literature, opening vacancies is costly in that the resources that could be otherwise devoted to producing goods are diverted to hiring. The unit costs of vacancy posting are given by $\kappa_{v}$. Firms open vacancies at the beginning of each period to find matches. When posting vacancies, firm $f$ takes the job filling probability as given by the measure of labour market tightness. The problem of firm $f$ is to choose the processes $c_{f t}, g_{f t}, s_{f t}^{c}, s_{f t}^{g}, P_{f t}, k_{f t-1}, v_{f t}$ so as to maximise the present discounted value of expected profits,

$$
E_{t} \sum_{\tau=t}^{\infty} Q_{t, \tau} P_{\tau} \phi_{f \tau},
$$

where $Q_{t, \tau}$ is the stochastic discount factor resulting from (46), subject to the technological constraint, equation (50), the law of motion of employment,

$$
n_{f t}=(1-\rho) n_{f t-1}+v_{f t} q\left(\theta_{t}\right),
$$

the private sector demand for good $f$, equation (52), (and its equivalent public sector demand, equation (53)), the demand for investment, equation (55), and the two laws of motion of the habit stocks, equations (36) and (54).

The first order conditions with respect to $c_{f t}, g_{f t}, s_{f t}^{c}, s_{f t}^{g}, P_{f t}, k_{f t-1}$ and $v_{f t}$ are respectively:

$$
\begin{gathered}
\frac{1}{\mu_{f t}}=\frac{P_{f t}}{P_{t}}-\nu_{f t}^{c}+\left(1-\vartheta_{c}\right) \psi_{f t}^{c}, \\
\frac{1}{\mu_{f t}}=\frac{P_{f t}}{P_{t}}-\nu_{f t}^{g}+\left(1-\vartheta_{g}\right) \psi_{f t}^{g}, \\
\psi_{f t}^{c}=\beta \vartheta_{c} E_{t} \frac{\lambda_{t+1}}{\lambda_{t}} \psi_{f t+1}^{c}+\beta \zeta_{c} E_{t} \frac{\lambda_{t+1}}{\lambda_{t}} \nu_{t+1}^{c}, \\
\psi_{f t}^{g}=\beta \vartheta_{g} E_{t} \frac{\lambda_{t+1}}{\lambda_{t}} \psi_{f t+1}^{g}+\beta \zeta_{g} E_{t} \frac{\lambda_{t+1}}{\lambda_{t}} \nu_{t+1}^{g}, \\
c_{f t}+g_{f t}+i_{f t}(1-\epsilon)+i_{f t} \frac{\epsilon}{\mu_{f t}}+\beta \kappa_{p} E_{t} \frac{\lambda_{t+1}}{\lambda_{t}} \frac{P_{f t+1}}{P_{f t} \tilde{\pi}_{t+1}}\left(\frac{P_{f t+1}}{P_{f t} \tilde{\pi}_{t+1}}-1\right) y_{t+1}= \\
=\nu_{f t}^{c} x_{t}^{c} \epsilon+\nu_{f t}^{g} x_{t}^{g} \epsilon+\frac{P_{f t}}{P_{f t-1} \tilde{\pi}_{t}}\left(\frac{P_{f t}}{P_{f t-1} \tilde{\pi}_{t}}-1\right) y_{t},
\end{gathered}
$$




$$
r_{k t}=\frac{F_{f t}^{k}}{\mu_{f t}}
$$

and

$$
\mathcal{J}_{f t}=\frac{\kappa_{v}}{q\left(\theta_{t}\right)}
$$

where

$$
F_{f t}^{k}=\left(\frac{y_{f t}}{k_{f t-1}}\right)^{\frac{1}{\eta}} \alpha_{k}\left(z_{k t}\right)^{\frac{\eta-1}{\eta}}
$$

is the marginal product of physical capital. $1 / \mu_{f t}, \nu_{f t}^{c}, \nu_{f t}^{c}, \psi_{f t}^{c}, \psi_{f t}^{g}$ and $\mathcal{J}_{f t}$ are the Lagrange multipliers associated with constraints (50), (52), (53), (36), (54) and (56) respectively. The shadow value of output, denoted by $1 / \mu_{f t}$, is the contribution of an additional unit of output to the profits of the firm. Alternatively, we can interpret $\mu_{f t}$ as a measure of mark-ups, defined as the price of good $f$ over its marginal cost of production. The variables $\nu_{f t}^{c}$ and $\nu_{f t}^{g}$ denote the inverses of the price elasticities of demand for private and public consumption respectively. The first order conditions with respect to private and public consumption, equations (57) and (58), set the inverse of the mark-up equal to the sum of three components. The first two terms denote the current period revenues associated with a marginal increase in sales. This is equal to the revenue, $P_{f t} / P_{t}$, obtained on the marginal sale net of the forgone revenue on inframarginal quantities, $\nu_{f t}$. The third component denotes the shadow value of future consumption. Absent nominal price rigidities, the awareness of high future profits, coupled with the notion that consumers form habit at the individual level, induces firms to give up current profits in order to lock-in new consumers into customer-firm relationships. Therefore, firms face a inter-temporal trade-off between current and future profits (see also Melina and Villa, 2014). The variables $\psi_{t}^{c}$ and $\psi_{t}^{g}$ are the marginal contributions of the habit stocks to an increase in profits expressed in terms of goods. These shadow values depend negatively on the price-elasticities and positively on the future values of the habit stock. Adding nominal price rigidities changes the pricing incentive of firms; we can, thus, formulate equation (61) to describe the dynamics of prices in the model with deep habits in an analogous way to the Keynesian Phillips curve. Equation (63) states that the marginal value of employment to firm $f$ must be equal to the marginal cost of posting a vacancy, which is equal to the unitary vacancy cost times the average number of periods it takes to fill an additional vacancy.

In addition, the non-arbitrage condition with respect to employment is

$$
\mathcal{J}_{f t}=\frac{F_{f t}^{\ell}}{\mu_{f t}} h_{f t}-\frac{W_{f t} h_{f t}}{P_{t}}+\beta(1-\rho) \frac{\lambda_{t+1}}{\lambda_{t}} \mathcal{J}_{f t+1},
$$

where $\mathcal{J}_{f t}$ denotes the marginal value of employment at the firm. This value is determined by the current flow value of employment at the firm, which in turn is equal to the marginal revenue product of employment net of wage costs plus the continuation value of employment at the firm. By combining (63) with (65), we can find an expression for the job creation condition

$$
\frac{\kappa_{v}}{q\left(\theta_{t}\right)}=\frac{F_{f t}^{\ell} h_{f t}}{\mu_{f t}}-\frac{W_{f t}}{P_{t}} h_{f t}+\beta(1-\rho) E_{t} \frac{\lambda_{t+1}}{\lambda_{t}} \frac{\kappa_{v}}{q\left(\theta_{t+1}\right)},
$$

where

$$
F_{t}^{\ell}=\left(\frac{y_{t}}{n_{t} h_{t}}\right)^{\frac{1}{\eta}} \alpha_{n}\left(z_{\ell t}\right)^{\frac{\eta-1}{\eta}}
$$

is the marginal product of labour. Equation (66) states that firm $f$ will expand employment up the point where marginal cost and benefit are equalised. A productivity innovation in this set-up increases the marginal revenue product of employment and in profits per hire, which in 
turn leads to vacancy creation. Fluctuations in mark-ups due to the presence of frictions, such as deep habits and nominal price rigidities, can change the firm's incentives for vacancy creation through shifts in the the marginal revenue product of employment.

\section{B.3 Wage Bargaining and Hours Worked}

Wages are determined by maximising the joint surplus of a match following a Nash bargaining protocol. Formally, wages are negotiated according to the following bargaining game

$$
\max _{W_{f t}} \mathcal{W}_{f t}^{\xi} \mathcal{J}_{f t}^{1-\xi}
$$

where $\xi$ denotes the nominal bargaining power of the worker. Since, in the process of wage negotiation, the worker and the firm take the price level $P_{t}$ as given, bargaining over the nominal or real wage is irrelevant. ${ }^{12}$ In other words, choosing the nominal hourly wage, $W_{f t}$, pins down the real hourly wage, $w_{f t}$, and viceversa. Without impediments to wage adjustments, the desired split of the surplus is achieved and this split turns out independent of the unit of account. The solution to the Nash bargaining problem is given by

$$
\xi \mathcal{J}_{f t}=(1-\xi) \mathcal{W}_{f t}
$$

The bargained real wage is thus

$$
w_{f t} h_{f t}=\xi\left[\frac{F_{f t}^{\ell}}{\mu_{f t}} h_{f t}+\kappa \beta(1-\rho) E_{t} \frac{\lambda_{t+1}}{\lambda_{t}} \theta_{t+1}\right]+(1-\xi)\left[\bar{b}+\chi \frac{h_{f t}^{1+\varphi}}{\lambda_{t}(1+\varphi)}\right] .
$$

Unlike in the Walrasian labour market setting, the real wage is a function of the marginal revenue product of employment, the opportunity cost of replacing the worker and the opportunity cost of being employed at firm $f$. The higher the bargaining power of firms, $(1-\xi)$, the higher the weight of the outside option, the higher wages and the lower profits. Following Thomas (2008) and Cantore et al. (2014), hours per workers are decided such that the marginal revenue product of labour equals the marginal rate of substitution

$$
\frac{F_{f t}^{\ell}}{\mu_{f t}}=\chi \frac{h_{f t}^{\varphi}}{\lambda_{t}}
$$

This condition states that hours worked are independent of the hourly wage. Note that, absent search frictions, the marginal product of labour equals both the marginal rate of substitution and the wage rate.

\section{B.4 Closing the Model}

We assume symmetry across firms and households and we define aggregate variables as averages. Therefore, $n_{f t}=n_{f t}^{j}=n_{t}, h_{f t}=h_{f t}^{j}=h_{t}, v_{f t}=v_{t}, c_{f t}^{j}=c_{f t}=c_{t}, g_{f t}=g_{t}, i_{f t}=i_{t}^{j}=i_{t}$, $k_{f t}=k_{t}^{j}=k_{t}, s_{f t}^{c}=s_{t}^{c}, \mu_{f t}=\mu_{t}, \psi_{f t}^{c}=\psi_{t}^{c}, \nu_{f t}^{c}=\nu_{t}^{c}, P_{f t}=P_{t}, W_{f t}^{j}=W_{f t}=W_{t}$ for all $t$. All households pay taxes for the amount $\bar{\tau}_{t}=\bar{\tau}_{t}^{j}$.

We close the model by specifying a monetary rule. The monetary authority is assumed to set the nominal interest rate $R_{t}$ following a Taylor interest rate rule of the form:

$$
\frac{R_{t}}{R}=\left(\frac{R_{t}}{R}\right)^{r_{r}}\left[\left(\frac{\pi_{t}}{\pi}\right)^{r_{\pi}}\left(\frac{y_{t}}{y_{t-1}}\right)^{r_{y}}\right]^{1-r_{r}} \exp \left(\varepsilon_{r t}\right), \quad \text { with } \quad \varepsilon_{r t} \sim N\left(0, \varsigma_{r}\right),
$$

\footnotetext{
${ }^{12}$ To save on notation we have removed the superscript $j$ in the $\mathcal{W}_{f t}$.
} 
where $r_{r} \in(0,1)$ captures the degree of inertia in monetary policy and $r_{\pi}$ and $r_{y}$ are positive constants. In addition, the government budget constraint is given by

$$
g_{t}+\left(1-n_{t}\right) \bar{b}+\frac{R_{t-1}}{P_{t}} B_{t-1}=\frac{B_{t}}{P_{t}}+\bar{\tau}_{t} .
$$

Finally, by adding together the households' budget constraints and firms' profits, we derive the following identity

$$
y_{t}=c_{t}+g_{t}+i_{t}+\kappa_{v} v_{t}+\mathcal{A}_{t}
$$

This market clearing condition simply says that aggregate output is consumed, invested and also used to pay for both vacancy costs, $\kappa_{v} v_{t}$, and price adjustment costs, $\mathcal{A}_{t}$. 


\section{B.5 Symmetric Equilibrium}

$$
\begin{aligned}
& m_{t}=\bar{m}_{t} v_{t}^{\gamma} \tilde{u}_{t}^{1-\gamma} \\
& q\left(\theta_{t}\right)=m_{t} / v_{t} \text {, } \\
& n_{t}=m_{t}+(1-\rho) n_{t-1}, \\
& \theta_{t}=\frac{v_{t}}{\tilde{u}_{t}}, \\
& \tilde{u}_{t}=1-(1-\rho) n_{t-1}, \\
& u_{t}=1-n_{t} \text {, } \\
& \lambda_{t}=\left[x_{t}^{c}-\ln \left(z_{c t}\right)\right]^{-\sigma}, \\
& x_{t}^{c}=c_{t}-\zeta_{c} s_{t-1}^{c} \text {, } \\
& x_{t}^{g}=g_{t}-\zeta_{g} s_{t-1}^{g} \text {, } \\
& 1=\beta R_{t} E_{t} \beta_{t, t+1} / \pi_{t+1}, \\
& \lambda_{t} q_{k t}=\beta E_{t} \lambda_{t+1}\left[r_{k t+1}+(1-\delta) q_{k t+1}\right] \text {, } \\
& \lambda_{t}=q_{k t} \lambda_{t} z_{i t}\left\{\left[1-\frac{\kappa_{i}}{2}\left(\frac{i_{t}}{i_{t-1}}-1\right)^{2}\right]-\kappa_{i} \frac{i_{t}}{i_{t-1}}\left(\frac{i_{t}}{i_{t-1}}-1\right)\right\}+ \\
& +\beta \kappa_{i} E_{t} q_{k t+1} \lambda_{t+1} z_{i t+1}\left(\frac{i_{t+1}}{i_{t}}\right)^{2}\left(\frac{i_{t+1}}{i_{t}}-1\right), \\
& y_{t}=\left[\alpha_{k}\left(z_{k t} k_{t-1}\right)^{\frac{\eta-1}{\eta}}+\alpha_{n}\left(z_{\ell t} n_{t} h_{t}\right)^{\frac{\eta-1}{\eta}}\right]_{2}^{\frac{\eta}{\eta-1}} \\
& y_{t}=c_{t}+g_{t}+i_{t}+\kappa_{v} v_{t}+\frac{\kappa_{p}}{2}\left(\pi_{t} / \tilde{\pi}_{t}^{p}-1\right)^{2} y_{t} \\
& k_{t}=z_{i t} i_{t}\left[1-\frac{\kappa_{i}}{2}\left(\frac{i_{t}}{i_{t-1}}-1\right)^{2}\right]+(1-\delta) k_{t-1} \text {, } \\
& s_{t}^{c}=\vartheta_{t-1}^{c}+\left(1-\vartheta_{c}\right) c_{t}, \\
& s_{t}^{g}=\vartheta s_{t-1}^{g}+\left(1-\vartheta_{g}\right) g_{t}, \\
& 1 / \mu_{t}=1-\nu_{c t}+\left(1-\vartheta_{c}\right) \psi_{c t}, \\
& 1 / \mu_{t}=1-\nu_{g t}+\left(1-\vartheta_{g}\right) \psi_{g t}, \\
& \psi_{t}^{c}=\vartheta_{c} E_{t} \beta_{t, t+1} \psi_{t+1}^{c}+\zeta_{c} E_{t} \beta_{t, t+1} \nu_{c t+1} \text {, } \\
& \psi_{t}^{g}=\vartheta_{g} E_{t} \beta_{t, t+1} \psi_{t+1}^{g}+\zeta_{g} E_{t} \beta_{t, t+1} \nu_{g t+1}, \\
& c_{t}+g_{t}=\nu_{t}^{c} x_{t}^{c} \epsilon+\nu_{t}^{g} x_{t}^{g} \epsilon+\pi_{t} / \tilde{\pi}_{t}^{p}\left(\pi_{t} / \tilde{\pi}_{t}^{p}-1\right) y_{t}-\kappa_{p} E_{t} \beta_{t, t+1} \pi_{t+1} / \tilde{\pi}_{t+1}^{p}\left(\pi_{t+1} / \tilde{\pi}_{t+1}^{p}-1\right) y_{t+1}- \\
& (1-\epsilon) i_{t}-\epsilon \frac{i_{t}}{\mu_{t}}, \\
& r_{k t}=\frac{F_{t}^{k}}{\mu_{t}} \\
& F_{t}^{k}=\left(\frac{y_{t}}{k_{t}}\right)^{\frac{1}{\eta}} \alpha_{k}\left(z_{k t}\right)^{\frac{\eta-1}{\eta}}, \\
& F_{t}^{\ell}=\left(\frac{y_{t}}{n_{t} h_{t}}\right)^{\frac{1}{\eta}} \alpha_{n}\left(z_{\ell t}\right)^{\frac{\eta-1}{\eta}} \\
& \kappa / q\left(\theta_{t}\right)=\frac{F_{t}^{\ell} h_{t}}{\mu_{t}}-w_{t} h_{t}+(1-\rho) E_{t} \beta_{t, t+1} \kappa / q\left(\theta_{t+1}\right), \\
& w_{t} h_{t}=\xi\left[\frac{F_{t}^{\ell} h_{t}}{\mu_{t}}+\kappa_{v}(1-\rho) E_{t} \beta_{t, t+1} \theta_{t+1}\right]+(1-\xi)\left\{\bar{b}+\chi\left(h_{t}\right)^{1+\varphi} /\left[(1+\varphi) \lambda_{t}\right]\right\}, \\
& \frac{F_{t}^{\ell}}{\mu_{t}}=\chi \frac{h_{t}^{\varphi}}{\lambda_{t}} \\
& \frac{R_{t}}{R^{*}}=\left(\frac{R_{t}}{R^{*}}\right)^{r_{r}}\left[\left(\frac{\pi_{t}}{\pi^{*}}\right)^{r_{\pi}}\left(\frac{y_{t}}{y_{t-1}}\right)^{r_{y}}\right]^{1-r_{r}} \varepsilon_{r t}, \\
& \ln \left(g_{t} / g\right)=\varrho_{g} \ln \left(g_{t-1} / g\right)+\varepsilon_{g t} \text {, } \\
& \ln \left(z_{c t}\right)=\varrho_{c} \ln \left(z_{c t-1}\right)+\varepsilon_{c t}, \\
& \ln \left(z_{i t}\right)=\varrho_{i} \ln \left(z_{i t-1}\right)+\varepsilon_{i t}, \\
& \ln \left(\bar{m}_{t} / \bar{m}\right)=\varrho_{m} \ln \left(\bar{m}_{t-1} / \bar{m}\right)+\varepsilon_{m t}, \\
& \ln \left(z_{\ell t} / z_{\ell}\right)=\varrho_{\ell} \ln \left(z_{\ell t-1} / z_{\ell}\right)+\varepsilon_{\ell t}, \\
& \ln \left(z_{k t} / z_{k}\right)=\varrho_{k} \ln \left(z_{k t-1} / z_{k}\right)+\varepsilon_{k t} \text {. }
\end{aligned}
$$




\section{B.6 Log-linearised Equations}

$$
\begin{aligned}
& \widehat{m}_{t}=\widehat{\bar{m}}_{t}+\gamma \widehat{v}_{t}+(1-\gamma) \widehat{\widetilde{u}}_{t}, \\
& \widehat{q}_{t}=\widehat{\bar{m}}_{t}+(\gamma-1) \hat{\theta}_{t} \text {, } \\
& \widehat{\theta}_{t}=\widehat{v}_{t}-\widehat{\widetilde{u}}_{t}, \\
& \widehat{m}_{t}=\frac{1}{\rho}\left[\widehat{n}_{t}-(1-\rho) \widehat{n}_{t-1}\right], \\
& \widehat{\widetilde{u}}_{t}=-\frac{(1-\rho) n}{\widehat{u}} \widehat{n}_{t-1} \text {, } \\
& \widehat{u}_{t}=-\frac{n}{u} \widehat{n}_{t}, \\
& \widehat{\lambda}_{t}=-\sigma\left(\widehat{x}_{t}^{c}-\widehat{z}_{c t}\right) \text {, } \\
& \left(1-\zeta_{c}\right) \widehat{x}_{t}^{c}=\widehat{c}_{t}-\zeta_{c} \widehat{s}_{t-1}^{c}, \\
& \left(1-\zeta_{g}\right) \widehat{x}_{t}^{g}=\widehat{g}_{t}-\zeta_{g} \widehat{s}_{t-1}^{g}, \\
& \widehat{\lambda}_{t}=\widehat{R}_{t}+E_{t}\left[\widehat{\lambda}_{t+1}-\widehat{\pi}_{t+1}\right] \text {, } \\
& \widehat{q}_{k t}=E_{t}\left[\widehat{\lambda}_{t+1}-\widehat{\lambda}_{t}+\widehat{r}_{k t+1}\right]+\beta(1-\delta) E_{t}\left[\widehat{q}_{k t+1}-\widehat{r}_{k t+1}\right] \text {, } \\
& \widehat{i}_{t}=\widehat{i}_{t-1}+\frac{1}{\kappa_{i}(1+\beta)}\left(\widehat{q}_{k t}+\widehat{z}_{i t}\right)+\frac{\beta}{1+\beta} E_{t} \widehat{i}_{t+1} \text {, } \\
& \widehat{y}_{t}=\bar{y}^{\frac{1}{\eta}-1}\left[\alpha_{k} z_{k} k\left(\widehat{z}_{k t}+\widehat{k}_{t-1}\right)+\alpha_{n} z_{n} n h\left(\widehat{z}_{n t}+\widehat{h}_{t}+\widehat{n}_{t}\right)\right] \text {, } \\
& \widehat{y}_{t}=\frac{c}{y} \widehat{c}_{t}+\frac{g}{y} \widehat{g}_{t}+\frac{i}{y} \widehat{i}_{t}+\frac{\kappa_{v} v}{y} \widehat{v}_{t}, \\
& \widehat{k}_{t}=\delta\left(\widehat{z}_{i t}+\widehat{i}_{t}\right)+(1-\delta) \widehat{k}_{t-1} \text {, } \\
& \widehat{s}_{t}^{c}=\left(1-\vartheta_{c}\right) \widehat{c}_{t}+\vartheta_{c} \widehat{s}_{t-1}^{c} \text {, } \\
& \widehat{s}_{t}^{g}=\left(1-\vartheta_{g}\right) \widehat{g}_{t}+\vartheta_{g} \widehat{s}_{t-1}^{g} \text {, } \\
& -\frac{1}{\mu} \widehat{\mu}_{t}=-\nu_{c} \widehat{\nu}_{t}^{c}+\left(1-\vartheta_{c}\right) \psi_{c} \widehat{\psi}_{t}^{c} \text {, } \\
& -\frac{1}{\mu} \widehat{\mu}_{t}=-\nu_{g} \widehat{\nu}_{t}^{g}+\left(1-\vartheta_{g}\right) \psi_{g} \widehat{\psi}_{t}^{g}, \\
& \widehat{\psi}_{t}^{c}=E_{t} \widehat{\lambda}_{t+1}-\widehat{\lambda}_{t}+\beta \vartheta_{c} E_{t} \widehat{\psi}_{t+1}^{c}+\frac{\beta \zeta_{c} \nu_{c}}{\psi_{c}} E_{t} \widehat{\nu}_{t+1}^{c}, \\
& \widehat{\psi}_{t}^{g}=E_{t} \widehat{\lambda}_{t+1}-\widehat{\lambda}_{t}+\beta \vartheta_{g} E_{t} \widehat{\psi}_{t+1}^{g}+\frac{\beta \zeta_{g} \nu_{g}}{\psi_{g}} E_{t} \widehat{\nu}_{t+1}^{g} \text {, } \\
& \frac{c}{y} \widehat{c}_{t}+\frac{g}{y} \widehat{g}_{t}+(1-\epsilon) \frac{i}{y} \widehat{i}_{t}+\epsilon \frac{i}{y} \frac{1}{\mu}\left(\widehat{i}_{t}-\widehat{\mu}_{t}\right)+\beta \kappa_{p} E_{t}\left[\widehat{\pi}_{t+1}-\omega \widehat{\pi}_{t}\right]= \\
& =\frac{\nu^{c} x^{c} \epsilon}{y}\left(\widehat{\nu}_{t}^{c}+\widehat{x}_{t}^{c}\right)+\frac{\nu^{g} x^{g} \epsilon}{y}\left(\widehat{\nu}_{t}^{g}+\widehat{x}_{t}^{g}\right)+\kappa_{p}\left(\widehat{\pi}_{t}-\omega \widehat{\pi}_{t-1}\right) \text {, } \\
& \widehat{r}_{k t}=\widehat{F}_{t}^{k}-\widehat{\mu}_{t} \text {, } \\
& \widehat{F}_{t}^{k}=\frac{1}{\eta}\left(\widehat{y}_{t}-\widehat{k}_{t-1}\right)+\frac{\eta-1}{\eta} \widehat{z}_{k t}, \\
& \widehat{F}_{t}^{\ell}=\frac{1}{\eta}\left(\widehat{y}_{t}-\widehat{n}_{t}-\widehat{h}_{t}\right)+\frac{\eta-1}{\eta} \widehat{z}_{n t}, \\
& -\mathcal{J} \widehat{q}_{t}=\frac{F^{\ell} h}{\mu}\left(\widehat{F}_{t}^{\ell}+\widehat{h}_{t}-\widehat{\mu}_{t}\right)-w h\left(\widehat{w}_{t}+\widehat{h}_{t}\right)+\beta(1-\rho) \mathcal{J} E_{t}\left[\widehat{\lambda}_{t+1}-\widehat{\lambda}_{t}-\widehat{q}_{t+1}\right] \text {, } \\
& w h\left(\widehat{w}_{t}+\widehat{h}_{t}\right)=\xi\left\{\frac{F^{\ell} h}{\mu}\left(\widehat{F}_{t}^{\ell}+\widehat{h}_{t}-\widehat{\mu}_{t}\right)+\kappa_{v}(1-\rho) \theta E_{t}\left(\widehat{\lambda}_{t+1}-\widehat{\lambda}_{t}-\widehat{\theta}_{t+1}\right)\right\}+ \\
& +(1-\xi) \chi(h)^{1+\varphi} /[(1+\varphi) \lambda]\left[(1+\varphi) \widehat{h}_{t}-\widehat{\lambda}_{t}\right] \text {, } \\
& \widehat{F}_{t}^{\ell}-\widehat{\mu}_{t}=\varphi \widehat{h}_{t}-\widehat{\lambda}_{t} \text {, } \\
& \widehat{R}_{t}=r_{r} \widehat{R}_{t-1}+\left(1-r_{r}\right)\left[r_{p} \widehat{\pi}_{t}+r_{y}\left(\widehat{y}_{t}-\widehat{y}_{t-1}\right)\right]+\varepsilon_{r t}, \\
& \widehat{z}_{c t}=\varrho_{c} \widehat{z}_{c t-1}+\varepsilon_{c t}, \\
& \widehat{z}_{i t}=\varrho_{i} \widehat{z}_{i t-1}+\varepsilon_{i t}, \\
& \widehat{g}_{t}=\varrho_{g} \widehat{g}_{t-1}+\varepsilon_{g t}, \\
& \widehat{\bar{m}}_{t}=\varrho_{m} \widehat{\bar{m}}_{t-1}+\varepsilon_{m t}, \\
& \widehat{z}_{\ell t}=\varrho_{\ell} \widehat{z}_{\ell t-1}+\varepsilon_{\ell t}, \\
& \widehat{z}_{k t}=\varrho_{k} \widehat{z}_{k t-1}+\varepsilon_{k t} \text {. }
\end{aligned}
$$




\section{Steady State}

$$
\begin{aligned}
& u=0.1, \\
& q=0.7 \text {, } \\
& \mathcal{C}=\frac{\kappa v}{y}=0.01 \text {, } \\
& n=1-u \text {, } \\
& \tilde{u}=1-(1-\rho) n, \\
& h=1 \text {, } \\
& y=1 \text {, } \\
& v=\frac{\rho n}{q}, \\
& \bar{m}=q\left(\frac{v}{\tilde{u}}\right)^{1-\gamma}, \\
& m=\rho n \text {, } \\
& R=\frac{\pi}{\beta}, \\
& r_{k}=\pi / \beta-(1-\delta), \\
& q_{k}=1 \text {, } \\
& \Gamma_{c}=\left(1-\vartheta_{c} \beta\right) /\left[\left(1-\vartheta_{c} \beta\right)-\left(1-\vartheta_{c}\right) \zeta_{c} \beta\right], \\
& \Gamma_{g}=\left(1-\vartheta_{g} \beta\right) /\left[\left(1-\vartheta_{g} \beta\right)-\left(1-\vartheta_{g}\right) \zeta_{g} \beta\right], \\
& k=(1-c-g-\mathcal{C}) / \delta \text {, } \\
& \mu=\left[\epsilon \delta k+\epsilon\left(1-\zeta_{c}\right) c \Gamma_{c}+\epsilon\left(1-\zeta_{g}\right) g \Gamma_{g}\right) /\left[\epsilon\left(1-\zeta_{c}\right) c \Gamma_{c}+\epsilon\left(1-\zeta_{g}\right) \Gamma_{g} g-c-g-(1-\epsilon) k \delta\right], \\
& \nu_{c}=(1-1 / \mu) \Gamma_{c} \\
& \nu_{g}=(1-1 / \mu) \Gamma_{g} \\
& \psi_{c}=\frac{\zeta_{c} \beta}{\left(1-\vartheta_{c} \beta\right)\left(1-\zeta_{c}\right) \nu_{c}}, \\
& \psi_{g}=\frac{\zeta_{g} \beta}{\left(1-\vartheta_{g} \beta\right)\left(1-\zeta_{g}\right) \nu_{g}} \\
& F^{k}=r_{k} \mu \text {, } \\
& S^{k}=\frac{F^{k} k}{y}, \\
& S^{\ell}=1-S^{k}, \\
& i=\delta k \text {, } \\
& \frac{w h n}{y}=\frac{S^{\ell}}{\mu}-\frac{\mathcal{C}}{\rho}[1-\beta(1-\rho)], \\
& \kappa=\frac{\mathcal{C} y}{v}, \\
& w=\frac{w n h y}{y h n}, \\
& \xi=\frac{(1-\bar{b}) \frac{w n h}{y}-\frac{S^{\ell}}{\mu(1+\varphi)}}{\frac{S^{n} \mu}{\mu(1+\varphi)}-\bar{b} \frac{w n h}{y}+\beta(1-\rho) \mathcal{C} \frac{n}{\tilde{u}}}, \\
& \chi=\frac{S^{\ell} y[c(1-\zeta)]^{-\sigma}}{\mu n h^{1+\varphi}}, \\
& \bar{b}=\tilde{b} w h, \\
& s^{c}=c \text {, } \\
& s^{g}=g \text {, } \\
& x^{c}=\left(1-\zeta_{c}\right) c \text {, } \\
& x^{g}=\left(1-\zeta_{g}\right) g \text {, } \\
& \lambda=x_{c}^{-\sigma} \text {, } \\
& \theta=\frac{v}{\tilde{u}} \text {. }
\end{aligned}
$$

